\title{
Concentrações anômalas de flúor em águas subterrâneas
}

\author{
Anomalous concentrations of fluorine in groundwaters
}

\author{
José Luiz Silvério da Silva ${ }^{1}$, Mariana Ribeiro Santiago ${ }^{2}$, Malva Andrea Mancuso ${ }^{3}$,Carlos \\ Alberto Löbler', Valderi Luiz Dressler ${ }^{5}$, Teresa Condesso de Melo ${ }^{6}$, Marcelo Goffermann ${ }^{7}$ \\ ${ }^{1}$ Professor Associado, Departamento Geociências, UFSM, Santa Maria, Brasil. \\ ${ }^{2}$ Doutoranda do Instituto de Pesquisas Hidráulicas, UFRGS, Porto Alegre, Brasil. \\ ${ }^{3}$ Professora Adjunta, Departamento de Ciências Agronómicas e Ambientais, UFSM, Frederico Westphalen, Brasil. \\ ${ }^{4}$ Geógrafo, Mestrando do Programa de Pós Graduação em Engenharia Ambiental, UFSM, Santa Maria, Brasil. \\ ${ }^{5}$ Professor Associado, Departamento de Química,UFSM , Santa Maria, Brasil. \\ ${ }^{6}$ Investigadora Instituto Superior Técnico, Universidade de Lisboa, Lisboa, Portugal \\ ${ }^{7}$ Companhia de Pesquisas de Recursos Minerais, Serviço Geológico do Brasil, Porto Alegre, Brasil.
}

\begin{abstract}
Resumo
Acredita-se que concentrações até 1,5 mg/L de flúor nas águas seja benéfico à saúde humana na prevenção de cáries dentárias de crianças. Porém, valores superiores seriam prejudiciais, podendo causar manchas nos dentes, fluorose dental, e deformação dos ossos. Através da revisão da literatura observou-se que valores anômalos desse elemento ocorrem em aquíferos cristalinos, porosos e cáusticos. O objetivo da presente pesquisa foi apresentar uma evolução dos conhecimentos em relação às concentrações anômalas de flúor em águas subterrâneas, fornecendo uma visão global, nacional, regional apresentando aportes ao conhecimento do Sistema Aquífero Guarani/SAG no Estado do Rio Grande do Sul. Esse sistema apresenta, localmente, águas com concentrações anômalas de flúor, em vários estados brasileiros acima dos padrões de consumo humano. Muitas hipóteses foram levantadas até o presente momento buscando esclarecer a origem destas concentrações. Porém, ainda não existe um consenso entre os pesquisadores. Observou-se uma boa relação espacial com águas de caráter sódico, sulfatadas elou cloretadas na Zona de Afloramento com a unidade Hidroestratigráfica Santa Maria, fossilífera. Estudos recentes no noroeste do estado apontam uma associação com águas mais salinas, localmente termais, nas zonas confinadas, associando a origem do flúor às formações Pré-SAG, portadoras de sais elou minerais sulfatados. A hipótese mais consensual sugere a existência de misturas com águas salinas profundas, indicando existirem zonas onde predominam os fluxos verticais em relação aos horizontais no SAG, associadas a diques e a possivelmente a Capacidade de Troca Iônica dos argilominerais em um processo geogênico, de origem natural.
\end{abstract}

Palavras-chave: Hipóteses, revisão, SAG, avanços no conhecimento.

\begin{abstract}
It is believed that concentrations up to $1.5 \mathrm{mg} / \mathrm{L}$ of fluorine in the waters are beneficial to human health in the prevention of dental caries in children. But higher values would be harmful and cause stains on teeth, dental fluorosis, and deformed bones. Through the literature review, it was noted that anomalous values of this element occur in crystalline, porous and karstic aquifers. The aim of this paper was to present an evolution of knowledge regarding fluoride anomalous concentrations, performing a case study on the Guarani Aquifer System/GAS. Locally the groundwater has high fluoride concentration in many Brazilian states above standards for human consumption. Many hypotheses were seeking to clarify the origin of these concentrations. However, there is still no consensus among researchers. There is a good relationship with sodic waters character, sulfated and/or chlorinated. Recent studies suggest an association with more saline, thermal waters in confined areas, associating the origin of fluoride to pre-SGA formations, carriers of salts and sulfated minerals. The most consensual hypothesis suggests the existence of mixtures with saline deep waters, indicating that there are areas where vertical flows predominate in relation to the horizontal at the GAS associated this natural process with the ion exchange capacity of the clay minerals Keywords: Hypotheses, review; GAS, advances in knowledge.
\end{abstract}

*silverioufsm@gmail.com

Recebido: 08/04/2014 Aceito: 08/04/2014 


\section{Introdução}

$\mathrm{D}$ o ponto de vista hidrogeológico, a qualidade da água subterrânea é tão importante quanto o aspecto quantitativo. A disponibilidade dos recursos hídricos subterrâneos para determinados tipos de uso depende, fundamentalmente da qualidade físico-química, biológica e radiológica. O estudo hidrogeoquímico tem por finalidade identificar as principais propriedades e constituintes das águas subterrâneas, procurando estabelecer uma relação com o meio físico, de acordo com Costa Santos (2008). Esse autor ainda considera que os fluoretos frequentemente são encontrados em pequenas concentrações nas águas subterrâneas. Sendo o mineral fluorita a principal fonte natural, primária em rochas ígneas plutônicas como os granitóides. Normalmente, ocorrem concentrações entre 0,1 a 1,5 $\mathrm{mg} / \mathrm{L}$ nas águas naturais, incluindo-se as águas subterrâneas, podendo chegar até $10 \mathrm{mg} / \mathrm{L}$ e, raramente a 50 mg/L (Hem, 1985), em águas muito sódicas com pouco cálcio. Em regiões áridas, os fluoretos podem aparecer em quantidades elevadas. A concentração do Cálcio (Ca) limita a concentração do ( $\left.\mathrm{F}^{-}\right)$. Esse elemento nas águas com concentrações até $1,5 \mathrm{mg} / \mathrm{L}$ parece ser benéfico à saúde humana Costa Santos, (2008), na prevenção de cáries dentárias de crianças em fase de crescimento, entretanto, acima deste teor já é prejudicial, causando manchas nos dentes (fluorose dental) e deformação dos ossos (Santiago e Silvério da Silva, 2011b).

Em relação aos padrões de potabilidade para consumo humano a Portaria Ministério da Saúde № 2.914/2011 estabeleceu como valor máximo permissível (VMP) a concentração de 1,5 mg/L (BRASIL, 2011), valor também adotado na Resolução Conama № 396/2008 (BRASIL, 2008). Já o Estado do Rio Grande do Sul, considera a faixa ótima para consumo humano teores entre 0,6 a $0,9 \mathrm{mg} / \mathrm{L}$ Portaria № 10/99 (Baccar, 1998; Bertazzo, 1999; Silvério da Silva et al., 2002; Santiago e Silvério da Silva, 2009 a,b).

A geoquímica das águas subterrâneas, também referida como hidrogeoquímica é uma ciência multidisciplinar que relaciona a composição química das águas aos processos e relações de subsuperfície. O enfoque principal da hidrogeoquímica é a compreensão da origem e evolução química dos constituintes presentes nas águas, em decorrência dos processos físico-químicos-biogeoquímicos que acontecem durante o fluxo das águas subterrâneas nos aquíferos, desde a zona de recarga na superfície do terreno até os exutórios naturais (Mestrinho, 2008).

No Brasil, de acordo com Santiago e Silvério da Silva (2009 a,b), já foram identificadas águas subterrâneas contendo concentrações anômalas de (F-), superiores a 1,5 mg/L, nos estados de Rio Grande do Sul, Santa Catarina, Paraná, São Paulo, Minas Gerais, Mato Grosso, Mato Grosso do Sul, Goiás, Tocantins e Rio de Janeiro. Tanto em aquíferos cristalinos fissurais associados aos granitóides, quanto em aquíferos porosos intergranulares em rochas sedimentares clásticas e ainda, em rochas carbonáticas formando aquíferos cársticos (Velásquez, 2002 e Velásquez et al., 2006).

Conforme poderá ser constatado na revisão da literatura sobre as concentrações anômalas de (F-) em águas subterrâneas ainda não há consenso entre os pesquisadores, em relação a sua origem, se natural geogênica ou antropogênica. Esse trabalho de revisão do estado da arte visa fornecer uma evolução e apresentar os avanços do conhecimento, tendo como hipótese de trabalho os elementos geológicos minerais aluminossilicáticos naturais, formadores das rochas reservatórios, associados a eventos tectônicos como os lineamentos tectônicos e diques intrusivos associados, como sendo a fonte primária de $\left(\mathrm{F}^{-}\right)$para as águas subterrâneas. Esse elemento tanto pode ter sua origem hidrotermal, bem como nos processos de intemperismo de minerais alumissilicáticos, sais (haletos), fosfatos ou ainda, associados a complexos sortivos em argilominerais com elevada Capacidade de Troca Cationnica/CTC. Ainda podem estar associados a mesclas de águas, doces e/ou salobras, em distintos reservatórios, porosos intergranulares associados as pressões piezométricas, aos falhamentos/diques e/ou surgências de águas de zonas mais profundas.

A Geologia Médica compreende o desenvolvimento de projetos em regime de parcerias, objetivando fornecer aos gestores da saúde pública, elementos para a correlação entre as anomalias geoquímicas naturais ou artificiais do meio físico (solo e água) e a incidência de endemias entre a população. A Geologia Médica visa apoiar a aplicação do conhecimento das Geociências a fim de superar problemas na área da saúde pública (CPRM/Serviço Geológico do Brasil, 2014), propiciando assim, a formulação de políticas preventivas. Portanto a hidrogeoquímica utiliza técnicas de prospecção de minérios associadas aos métodos analíticos, com uso de diversos tipos de equipamentos na caracterização de minerais, rochas e águas. Destacando-se estudos desde a escala da lupa binocular (80X=magnificações), a microscopia óptica (Luz Natural e Luz Polarizada) em lâminas delgadas (500X), a Microscopia Eletrônica de Varredura/MEV, Espectroscopia de Energia Dispersiva EDS (5.000X), em amostras de minerais, fragmentos ou lâminas delgadas, ou de calha (coletadas durante a perfuração de poços tubulares) metalizadas com carbono ou ouro/paládio são técnicas não destrutivas. Já as análises solos, sedimentos ou minerais e também de águas, são utilizadas técnicas como o Inductively Coupled Plas$\mathrm{ma} / \mathrm{ICP}$ Mass Espectometer/MS, e o OS (para as águas salobras, ricas em sódio), complementadas por usos de técnicas isotópicas, utilizando-se Sistema de Informações Geográficas e Geoestatística na espacialização dos resultados analíticos.

No entanto, deve-se salientar que o flúor (F-) trata-se de um elemento químico que não tem outros isótopos, podendo usar-se razões iônicas como Cl/BR Vengosh; Pankratov (1998) na avaliação da sua origemAs águas subterrâneas apresentando elevadas concentrações de 
(F-) ocorrem em diversos aquíferos, em vários continentes, e pode estar associada a uma variedade de terrenos geológicos:

1- Rochas de composição granitóide-gnáissicas (China, Coréia, Sri Lanka, Tailândia, Índia, Paquistão, África, Reino Unido, Noruega, EUA);

2- Rochas de composição vulcânica e/ou alcalina (Rift Valley África Oriental, Etiópia, Uganda, Sudão, Jordânia, Havaí (condensados vulcânicos), Índia, China e México);

3- Rochas sedimentares minerais evaporatos, calcretes e sepiolita-paligorsquita: Argélia, Etiópia, Espanha, EUA, Europa, Marrocos, Quênia Handa, (1975); Hem, (1985); Jack et. al. (1993); Gaciri and Davies, (1993); Ashley and Burley (1995); Dissanayake, (1996); Ampabire et. al. (1997); Banks et. al. (1998); Ojeda y González, (1998); Jacks et. al. (1999); Hurtado et al. (2004), Kim and Jeong, (2005); WHO (2006); Chae et al. (2007); Wang et al. (2008), Guo et al. (2009). WHO (2006) cita ocorrências de fluorose dental e esqueletal associadas a exposições de (F-) através da água de consumo humano em 28 países: 1) Argentina, 2) Brasil (Estado da Paraíba no Município de Olho D’Água Cortês et al. (1996)) 3) Canadá, 4) China, 5) Eritréia, 6) Etiópia, 7) Alemanha, 8) Índia, 9) Indonésia, 10) Israel, 11) Japão, 12) Quênia, 13) México, 14) Niger, 15) Nigéria, 16) Noruega, 17) Paquistão, 18) Arábia Saudita, 19) Senegal, 20) África do Sul, 21) Espanha, 22) Sri Lanka, 23) Sudão, 24)Tailândia, 25) Turquia, 26) Uganda, 27) República Unida da Tanzânia e 28) Estados Unidos da América.

Jack et al. (1999) indicaram que no sul da Índia e no Leste da África, regiões de características áridas, apresentam as mais extensas áreas de águas subterrâneas apresentando elevadas concentrações de (F-). Acreditavam que o mecanismo de acumulação desse elemento, fosse essencialmente derivado do intemperismo de minerais aluminossilicatos, sendo a deposição atmosférica comparavelmente pequena. Appelo and Postma (2006) citando esses autores dizem que... "a fluorose é uma disfunção comum no Rift Valley Africano e países como Quênia e a Etiópia, onde as fontes vulcânicas de ( $\left.\mathrm{F}^{-}\right)$são importantes, bem como na Índia e Oeste da África, onde os sais e minerais sedimentares com ligação (F-) são as fontes primárias. No sul da Índia, cerca de 67 milhões de pessoas estariam em risco de desenvolvimento de fluorose".

No Brasil, Silvério da Silva et al. (2006) e Santiago (2010) indicaram a existência de águas subterrâneas com concentrações anômalas de ( $\left.\mathrm{F}^{-}\right)$nos três tipos de aquíferos: a) poroso intergranular/sedimentar clásticas ou terrígenas (Ex. Sistema Aquífero Guarani/SAG); b) fraturado/fissural (Ex. Aquífero Cristalino, nos Estados de São Paulo, Rio de Janeiro, Paraíba) e ainda, nas rochas vulcânicas da Formação Serra Geral da Bacia Sedimentar do Paraná, c) Cárstico/karst (Grupo Bambuí) no norte do Estado de Minas Gerais.

Em relação a origem de ocorrências anômalas de flúor em águas subterrâneas da Bacia Sedimentar do Paraná, destacam-se os estudos nos estados de São Paulo/SP e no Paraná/PR, Giampá e Franco Filho (1982); Silva et al. (1982); Silva (1983); Perroni et al. (1985); IPT (1986), Kimmelmann et al. (1990); Fraga e Lisboa (1990); Celligoi e Duarte (1992); Fraga (1992), Araújo et al. (1999), Sracec e Hirata (2002), PSAG/OEA (2009 b,c), Mocellin (2009), Hypholito et al. (2010).

Em escala regional no Estado do Rio Grande do Sul estudaram as concentrações anômalas de (F-) em águas subterrâneas associadas as rochas vulcânicas da Formação Serra Geral: Martins (1979), Abreu (1981), Lisboa e Menegotto (1999), Nanni (2006), Nanni et al. (2008a, 2008b, 2013), Frank et al. (2007); Mancuso et al. (2013). Já autores como Lobo e Costa (1998), Baccar (1998), Lobo et al. (2000), Machado (2005), Machado e Freitas (2005 e 2008), Kern et al. (2008), Silvério da Silva et al. (2000, 2002, 2008, 2011a, 2011b), Marimon (2006), Santiago e Silvério da Silva (2009, 2010, 2011a, 2011b), Santiago (2010) trabalharam as rochas sedimentares clásticas. Enquanto, Goffermann (2013) trabalhou com rochas cristalinas do escudo e também nas rochas sedimentares porosas do Pré-SAG.

Velásquez et al. (2006) destacaram a ocorrência de fluorose dental associada ao Grupo Bambuí, onde ocorre o mineral fluorita no Município de São Francisco Estado de Minas Gerais.

Atualmente, em função do crescente número de pesquisas relativas às concentrações de $\left(\mathrm{F}^{-}\right)$, bem como resultados de um maior número de análises físico-químicas como resultado de outorgas de usos de águas para consumo humano, em vários estados brasileiros. O Decreto Estadual no 42.047, de 26 de dezembro de 2002, regulamenta disposições da Lei no 10.350 , de 30 de dezembro de 1994, com alterações, relativas ao gerenciamento e à conservação das águas subterrâneas e dos aquíferos no Estado do Rio Grande do Sul. A partir desses novos resultados, houve crescimento nos estudos que permitiram a identificação de casos de fluorose em várias partes do país Santiago, Silvério da Silva (2009). Cortês et al. (1996) indicaram existência de fluorose dental no Município de Olho D’Água no Estado da Paraíba. Posssivelmente associadas a rochas cristalinas. Toassi e Abegg (2005) citam ocorrências de fluorose dental endêmica nas cidades de Pereira Barreto, Icém, Cosmópolis e São João do Pau d'Alho no Estado de São Paulo e em Cocal do Sul em Santa Catarina. Geomorfologicamente o Município de Santa Tereza está situado na zona de transição entre a Depressão Central e a serra gaúcha. Observou-se nesse último que as captações por poços tubulares cadastrados no SIAGAS/CPRM (2014) penetram a porção confinada do SAG, (ZFC) e (ZC) ou rochas vulcânicas do SASG. Entre os 19 poços cadastrados nesse município, apenas um (4300010781), apresentou concentração de $\left(\mathrm{F}^{-}\right)$de 1,2 mg/L, estando fora de padrão 
de consumo humano considerando-se a legislação do Estado do RS. Localiza-se na sede municipal, em cota altimétrica $84 \mathrm{~m}$ acima do nível médio do mar e penetra somente o SASG em cerca de $74 \mathrm{~m}$.

A ampliação do conhecimento sobre ocorrências de (F-), vem ocorrendo em função de um controle mais eficaz da qualidade da água subterrânea consumida pela população através das Vigilâncias Sanitárias Municipais Martins Netto et al. (2004). O aumento do controle quanto à qualidade da água pode estar relacionado, também à ampliação do número de processos de outorgas de direito de uso de águas subterrâneas nos estados. Salienta-se que algumas águas minerais envasadas, apresentam concentrações deste elemento acima VMP para consumo humano. Visto que, são regidas por outra legislação específica, por serem águas minerais e apresentarem algum elemento químico em concentrações que seja benéfico à saúde humana, Santiago (2010). Informa-se aos leitores que todas as águas minerais envasadas ou fontes hidrominerais encontram-se no sítio do Departamento Nacional da Produção Mineral/ Banco de Dados das Fontes Hidrominerais do Brasil de e (Brasil /DNPM/ SIGHIDRO/2014), obs. sugere-se na sua pesquisa o uso do navegador Internet Explorer.

De acordo com Andreazzini et. al. (2006 apud Bell, 1998) a ocorrência do (F-) estaria relacionada comumente aos processos ígneos. Durante a evolução magmática, $\mathrm{o}\left(\mathrm{F}^{-}\right)$ocorre geralmente como um componente da fase volátil, concentrando-se nas fases finais da evolução em rochas alcalinas, carbonatitos, depósitos hidrotermais, zonas de alteração e pegmatitos, geralmente como mineral fluorita e fluorapatita. Liberado pelo intemperismo dos minerais aluminossilicatados, o ( $\left.\mathrm{F}^{-}\right)$passaria a fazer parte das soluções aquosas supergênicas, na forma do íon fluoreto, livre dissolvido ( $\left.\mathrm{F}^{-}\right)$, com alta mobilidade. Na faixa dos baixos valores de $\mathrm{pH}$ ácidos, pode ser estável à espécie HF. Nas águas subterrâneas, sua concentração pode variar desde menos que 1,0, a mais de 35,0 (mg/L) (F-). Enquanto em águas correntes e em lagos, geralmente, as concentrações são baixas entre (0,01 - 0,30 mg/L) (Hem, 1985).

Deve-se salientar que, uma das principais conclusões do II Congresso do Aquífero Guarani, realizado na cidade de Ribeirão Preto, Estado de São Paulo, (PSAG, 2008) indicaram que: há problemas em algumas áreas restritas com relação às concentrações de $\left(\mathrm{F}^{-}\right)$, arsênico, e salinidade. Visto que, esses parâmetros necessitam de estudos de escala regional e local da captação, seja ela um poço tubular, um poço escavado. Ainda uma surgência, a qual pode trazer elementos químicos dispersos em condições de baixa salinidade e/ou salobras.

O Projeto PSAG/OEA/PEA(2009) sugere três zonas de gestão. Na Zona de Afloramento (ZA) ocorrem afloramentos de rochas sedimentares arenosas, siltosas e argilosas, de Idades Permo-Triássicas, formando aquíferos porosos intergranulares de distintas relações de porosidade/ permeabilidade, essa bordeja a zona de confinamento.
A Zona de Confinamento (ZC) é aquela constituída por uma cobertura de derrames de rochas vulcânicas da Formação Serra Geral, atualmente denominado de Sistema Aquífero Serra Geral/SASG (Machado e Freitas, 2005). A espessura dos derrames até $100 \mathrm{~m}$. Já a Zona de Forte Confinamento (ZFC) apresenta uma espessura das rochas vulcânicas (SASG) superior aos $100 \mathrm{~m}$. Tanto a (ZC) quanto a (ZFC) formam aquíferos cristalinos fissurais, podendo estar associados a rochas efusivas vulcânicas de composição básica toleítica (basaltos) e ácidas (riólitos/riodacidos). Essas são constituídas por distintos minerais aluminissilicatos. Por exemplo, os feldspatos alcalinos e/ou os plagioclásios podem ser fontes, tanto de elementos maiores como o: Cálcio, quanto de Sódio (Na) para as águas, bem como de Magnésio $(\mathrm{Mg})$ e mais raramente potássio (K). Porém, apresentam baixas concentrações de cloro e de flúor. Já minerais como olivinas, piroxênios, anfibólios, micas podem ser fontes primárias de (Ferro/Fe; Manganês/Mn, diversos outros metais e metaloides, bem como Elementos Terras Raras/ETRS (leves e pesadas), os quais não serão discutidos). Por outras rochas de composições alcalinas, podem apresentar-se enriquecidas em fases tardias do resfriamento do magma, ex. formando pegmatitos, com minerais bem desenvolvidos de tamanho centimétrico a métrico, ex. topázio e fluorita que contém flúor primário.

Convém salientar que até o presente momento existem diversas hipóteses alternativas que buscam explicar a origem do $\left(\mathrm{F}^{-}\right)$, em águas subterrâneas com concentrações anômalas. Sendo a origem geológica (geogênica) mais aceita, do que a antropogênica a partir de contribuições atmosféricas, por exemplo, uso de fertilizantes nitrogenados a base de NPK contendo flúor. Outra fonte que não deve ser desconsiderada, seria próximo as olarias que utilizam argilas de intemperismo de rochas alcalinas (Maddock e Dias 1988, 1989) e ainda nas pastagens próximas a esses empreendimentos (Magalhães, 1982, Panagoulias e Silva Filho, 2006), ex. região do Município de Itaboraí, RJ.

Wang et al. (2009) propuseram duas hipóteses para águas sódicas: a primeira de origem geológica. A outra na troca catiônica de $\mathrm{Ca}^{2+} \rightarrow \mathrm{Na}^{+}$, contudo relataram que ambas apresentam deficiências. Goffermann (2013) apoia essa hipótese, através de ensaios de solubilização/ lixiviação demonstrou a intensa troca de cátions entre os sedimentos argilosos dos aquíferos Pré -SAG (Rio Bonito) e Pirambóia com as águas subterrâneas, permitindo a dessorção do sódio para a água subterrânea e a adsorção de cálcio pelos argilominerais, da família das esmectitas, devido a sua elevada CTC Drever (1997), Appelo and Postma (2006).

Marimom (2006) estudou o sistema solos-água na (ZA) do SAG, no Estado do Rio Grande do Sul. Investigou a possível origem antropogênica, numa área de maior produção de tabacos do país, utilizando técnicas modernas de isótopos estáveis, concluindo ser esse elemento de origem natural na Unidade Hidroestratigráfica 


\section{Santa Maria.}

Apresentar uma revisão sistemática das principais hipóteses sobre a origem do (F-) em águas subterrâneas, com ênfase no SAG nos Estados do RS e SC, utilizando resultados do Consórcio Guarani Projeto PSAG (2009 $a, b, c)$, dissertações, teses, trabalhos de graduação. Apresentar uma revisão dos avanços do conhecimento bem como apresentar os principais resultados obtidos no Labhidrogeo/Laboratório de Geologia Ambiental, Laqia/ Laboratório de Química Industrial e Ambiental UFSM/ Santa Maria e do Grupo de Engenharia Ambiental UFSM/ Frederico Westphalen/FW/CESNOR.

Visando à ampliação do conhecimento e espacialização das ocorrências anômalas de (F-) de acordo com as características geológicas, hidroquímicas das captações. Na escala Regional a Figura 1 inclui estados de RS e SC, a partir de amostras de água avaliadas pelo Consórcio Guarani PSAG (2009c).

Millani et al. (2007) discutiram as Sinéclises Paleozóicas incluindo Sedimentar do Paraná citando as ocorrências da Formação Irati (folhelhos betuminosos, margas, carbonatos e contendo depósitos de evaporitos (camadas de sais (Haletos), subordinados). Os contextos flúvio-lacustres que devido ao ressecamento progressivo teriam evoluído no Triássico para desertos arenosos, citando as formações Pirambóia e Sanga do Cabral. Na Bacia do Paraná, extensiva deflação eólica perduraria até o Eocretáceo. Esta condição estaria registrada nos sedimentos da Formação Botucatu, preservados no registro geológico por terem sido recobertos pelo pacote de lavas da Formação Serra Geral. Como precursores da ruptura do Gondwana, os diques, as soleiras, e derrames de rochas ígneas acomodaram-se em grandes volumes. Deve-se registrar em primeiro, a não existência ou não identificação de evaporitos na Formação Botucatu. Em segundo, que os diques, as soleiras e as emanações vulcânicas tardias, poderiam representar localmente uma fonte de minerais contendo $\left(\mathrm{F}^{-}\right)$.

Nessa pesquisa será enfatizada a (ZA) do SAG, numa extensão de cerca de $250 \mathrm{~km}$ (Figura 2). A mesma apresenta uma disposição Leste-Oeste, coincidindo com a Depressão Central do estado do RS, e está situada entre os Municípios de Taquari e São Pedro do Sul. Também serão apresentadas as águas com concentrações anômalas na (ZC) (ZFC) que confinam os arenitos do SAG, PSAG (2009 a,b,c) produzidas pelo Consórcio Guarani nos Estados de SC e RS (2004). De acordo com PSAG/ PEA (2009 a, b) o SAG apresenta três zonas de gestão. $\mathrm{Na}(\mathrm{ZA})$ ocorrem afloramentos de arenitos, arenitos argilosos, siltitos e argilitos formando aquíferos porosos intergranulares, livres a semi-confinados, por espessas camadas argilosas contendo ossos fósseis répteis da Era Mesozóica da Formação Santa Maria. Essa unidade hidroestratigráfica Alemoa (Aquiclude, não transmite água) ocorre somente na porção central do Estado do RS CPRM (2008). Enquanto na (ZC) as unidades hidroestratigráficas sedimentares estão confinadas por rochas vulcânicas da
Formação Serra Geral, com espessura inferior a 100m. Conforme já apresentado na (ZFC) ocorrem espessos derrames de rochas vulcânicas de espessura superior a $100 \mathrm{~m}$ até mais de $1.500 \mathrm{~m}$, no centro da Bacia do Paraná.

Nessa pesquisa será brevemente apresentada uma visão mundial e no Brasil das concentrações anômalas de $\left(\mathrm{F}^{-}\right)$em diferentes aquíferos (porosos/intergranulares, cristalinos/fissurais e cársticos). Adotou-se à coluna estratigráfica proposta por Machado (2005), Machado e Freitas (2005) Mapa Hidrogeológico do Estado RS e do mapa Geológico da CPRM (2008), Figura 2.

Em relação às principais estruturas tectônicas Machado (2005) e Machado e Freitas (2005) concluíram que as formações Santa Maria e Caturrita afloram somente no bloco central do Estado do Rio Grande do Sul, limitado por falhas de borda de rift. O limite Oeste é dado pelo "Sistema de Falhas Jaguari-Mata - SFJM", de direção NW, enquanto o bloco Leste teria sofrido reativação da "Zona de Cisalhamento Transcorrente Dorsal de Canguçu - SFDC", de direção NE e idade Pré-Cambriana. Já o "Sistema de Falha Terra de Areia - Posadas/SFTA-P" apresenta direção NW sendo um possível delimitador do rift, a Norte. As litofácies desta unidade ocorrem no Sul e Sudoeste (poços ITRS e RI-RS), não se estendendo para Norte e Nordeste. Uma das áreas a serem discutidas no presente estudo situa-se no bloco central do estado coincidindo com a (ZA) do SAG.

Machado (2005), no Estado do RS, considerou o SAG constituído por nove unidades hidroestratigráficas: 1) Pirambóia; 2) Sanga do Cabral; 3) Passo das Tropas 1; 4) Passo das Tropas 2; 5) Alemoa; 6) Caturrita; 7) Arenito Mata; 8) Botucatu e 9) Guará. Dentre estas, a única que não ocorre na área do estudo é a unidade hidroestratigráfica Guará. Esta última ocorre na região Oeste do estado, nos Municípios de Santana do Livramento, Quaraí, Alegrete, São Francisco de Assis, avaliadas em Silvério da Silva et al. (2007) no Projeto PSAG, fundo das universidades em cooperação com a UDELAR/Uruguai. Devendo-se salientar que nesta porção do estado, não haviam sido encontradas águas subterrâneas com concentrações anômalas de ( $\left.\mathrm{F}^{-}\right)$, durante a execução do referido projeto binacional.

Merece ser referido que as unidades hidroestratigráficas correspondentes aos Aquíferos Passo das Tropas 1, Passo das Tropas 2, e Aquiclude Alemoa, fazem parte da Formação Santa Maria (Membro Passo das Tropas e Membro Alemoa) da era Mesozóica, Período Triássico.

O Membro Passo das Tropas constitui um dos melhores aquíferos na região do Município de Santa Maria (CPRM, 1994).

Já o Membro Alemoa só ocorre no Estado do RS, apresentando um vasto registro fossilífero contendo vários sítios contendo répteis fósseis Triássicos Barberena (1987), Von Huene (1990), Böger und Kowalczyk (1993). Esta unidade hidroestratigráfica constitui um Aquiclude e é formada por camadas silto-argilosas, vermelhas com 


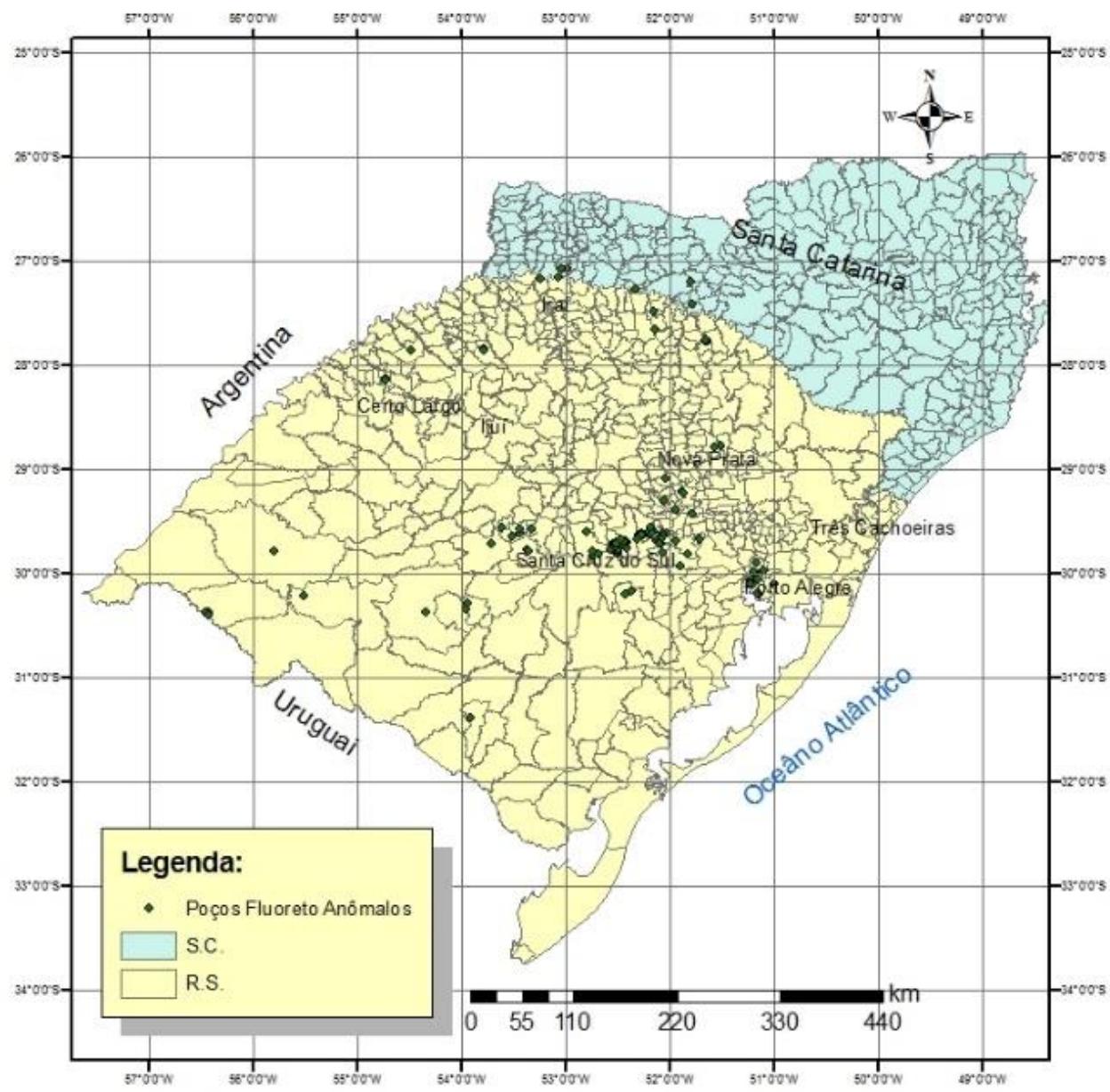

Figura 1- Mapa ilustra vista das concentrações de anômalas (F-) estados RS e SC, Santiago (2010).

caliches ${ }^{1}$, calcretes e silcretes Silvério da Silva (1997), Silvério da Silva et al. (1990). Estudos realizados por $\mathrm{MEV}$, encontrou-se em uma amostra a ocorrência de microcristais de Halita ( $\mathrm{NaCl}$ ) Silvério da Silva (1997).

$\mathrm{Na}$ fase inicial dos estudos das ocorrências anômalas de (F-) em águas subterrâneas na (ZA) do SAG, no RS, observou-se uma associação espacial, entre os argilitos vermelhos, os sítios fossilíferos, contendo ossos de répteis fósseis, calcretes e silcretes da unidade Hidroestratigráfica Alemoa. Estudos realizados por Silvério da Silva et al. (2002), com auxílio de técnicas DRX, indicaram ocorrências de fluorapatita em ossos de répteis fósseis de Idade Triássica da Era Mesozóico contendo elevado conteúdo em ( $\left.\mathrm{F}^{-}\right)$.

Nessa fase observou-se a ocorrência de poços com concentrações anômalas de $\left(\mathrm{F}^{-}\right)$associados aos pacotes de argilas vermelhas da Formação Santa Maria (Aquiclude Alemoa) portadora de ossos de répteis fósseis, localmente com fluorapatita. Os quais dependendo do avanço do processo de fossilização apresentaram até $31.261,7 \mathrm{ppm}$ ${ }^{1}$ Mayer, R. (1987). O termo caliche é sinônimo de calcrete, concrecionamento calcário que se desenvolve em um solo ou um alterito, termo utilizado para designar acumulações em meio continental: dolocrete (dolomita), silcrete (sílica), ferricrete (óxidos de ferro), alcrete (hidróxidos de alumínio), gipsecrete (gipso), etc. de (F-). Salienta-se que esta unidade hidroestratigráfica (Aquiclude) só ocorre na porção do bloco central do Estado do RS (Figura 2).

Brézillon (1969) diz "o fosfato de cal, principal constituinte dos ossos e dos dentes, apresenta grandes afinidades com o ( $\left.\mathrm{F}^{-}\right)$. No decurso de sua fossilização, os ossos e os dentes fixam progressivamente esse elemento, que se encontra no estado de fluoretos nas águas que infiltram nos solos. Informa que no ano de 1893, A. Carnot tentou utilizar essa propriedade para estabelecer um índice de fossilização, dos ossos segundo seu teor de flúor e estabelecer assim as bases de uma cronologia absoluta.

Deve-se informar que existem nos solos/rochas sedimentares três diferentes tipos de apatitas (Hidróxi-apatitas, Cloro-apatitas e Flúor-apatitas), sua composição pode estar relacionada com os elementos disponíveis em solução na água intersticial e/ou subterrânea, associadas as fases argilosas (alta porosidade e baixa permeabilidade), que facilita sua preservação.

Soares et al. (2008 a e b) sugerem interpretações estratigráficas diferentes às de Machado (2005) e Machado e Freitas (2005), para o SAG no Estado do RS, adotadas nesse estudo.

A Figura 2 ilustra a zona central, (ZA) do SAG no 


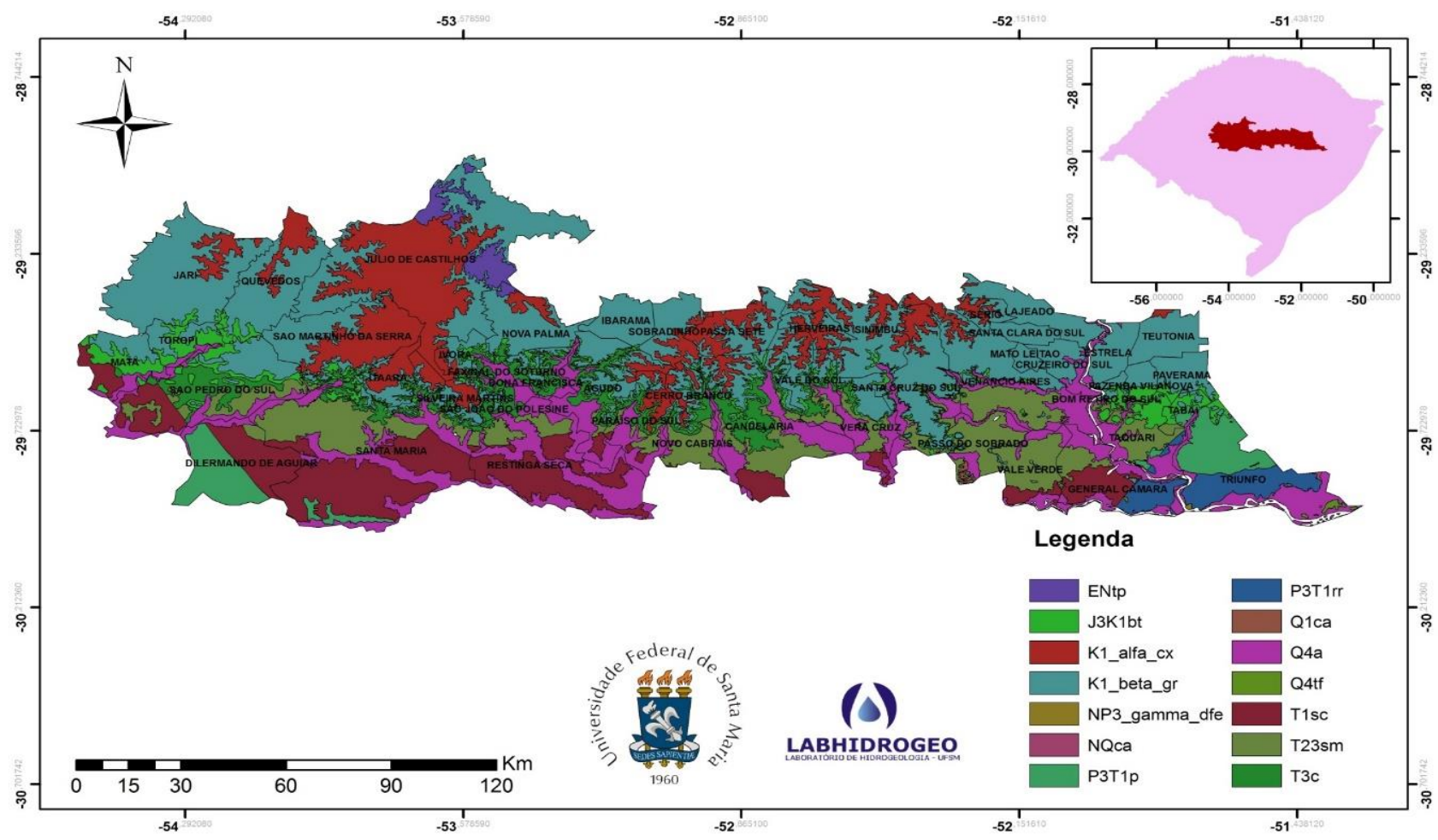

Figura 2- Localização dos principais Municípios de concentrações anômalas de (F-), acima do VMP, Portaria N. 2.914/2011, na Depressão Central, (ZA) do SAG. Fonte: Mapa Geológico CPRM (2008). Detalhes da legenda e cores em http://www.cprm.gov.br/geobank. Ex. \{J3k1bt =Formação Botucatu, T1 sc=Fm. Sanga do Cabral, T23sm=Fm. Santa Maria, T3c=Fm. Caturrita (=SAG) \}; $\{$ K1_alfa_cx (fácies Caxias) e K1_beta-gr =Fm. Serra Geral $(=\mathrm{SASG})\}$

Estado do RS, onde ocorrem diversas ocorrências de flúor anômalas em águas subterrâneas captando a Unidade Hidroestratigráfica Santa Maria. Sua orientação é aproximadamente Leste-Oeste, com cerca de $250 \mathrm{~km}$ de extensão, bordejando a (ZC) do SASG Santiago (2010).

\section{Método}

Apresentar uma revisão do estado da arte sobre ocorrências anômalas de concentrações de (F-) em águas subterrâneas, com ênfase para aquelas que fazem parte dos reservatórios do SAG. Apresentar uma análise, relativa às informações referentes aos Aquíferos PréSAG (Grupo Passa Dois, Subgrupo Estrada Nova, de constituição arenosa e argilosa) base do SAG. Também considera-se as rochas vulcânicas pertencentes ao Sistema Aquífero Serra Geral/SASG), nos estados do Rio Grande do Sul e Santa Catarina (Figura 1) as quais fazem parte da (ZC) e da (ZFC) SAG, quando penetram esse sistema.

Um detalhamento das zonas de gestão bem como aspectos hidroquímicos devem ser buscados em PSAG/ OEA $(2009$ b,c).

Foram avaliados os resultados constantes nos Periódicos CAPES (Trabalhos de graduação, dissertações e teses), artigos publicados em congressos, bem como resultados obtidos durantes o PSAG/OEA (2009 a, b, c) e outros relatórios.

Visando ampliar o conhecimento adotou-se a proposta de gestão do PSAG (2009 a, b, c) incluindo-se os aspectos hidroquímicos. Como resultados dos avanços no conhecimento consideraram-se os três tipos básicos de águas: Tipo A, Tipo B e Tipo C.

Tipo A: $\mathrm{Ca}-\mathrm{HCO}_{3}$ ou CaMg- $\mathrm{HCO}_{3}$, baixa mineralização. Subgrupos A1: $\mathrm{Na}^{+}>\mathrm{Cl}^{-}$e o $\mathbf{A 2}$ : $\mathrm{Na}^{+} \leq \mathrm{Cl}^{-}$.

Tipo B: $\mathrm{Na}-\mathrm{HCO}_{3}$, média a baixa mineralização. Composição: $\mathrm{Ca}^{2+} \rightarrow \mathrm{Mg}^{2+} \rightarrow \mathrm{Na}+$ adsorvido em argilominerais de arenitos do SAG.

Subgrupo B1: $\mathrm{Cl}-<\mathrm{SO}_{4}^{2-}\left(\Rightarrow \mathrm{SO}_{4}^{2-}\right.$ ), o SAG não contém sulfetos, nem evaporitos identificados até o presente. A fonte de sulfato seriam o gipso $\left(\mathrm{CaSO}_{4} \cdot 2 \mathrm{H}_{2} \mathrm{O}\right)$ e a jarosita (CaSO4.2H2O). São formações pertencentes as formações sedimentares arenoargilosas Pré-SAG, indicando fluxos ascendentes, com misturas de águas).

Subgrupo B2: Cl- > SO42-.

Tipo C: $\mathrm{Na}-\mathrm{HCO}_{3}-\mathrm{SO}_{4}-\mathrm{Cl}$ e Na-Cl e/ou Na-SO . Subgrupos C1: $\mathrm{Cl}-<\mathrm{SO}_{4}^{2-}$; o $\mathrm{C} 2$ : $\mathrm{Cl}->\mathrm{SO}_{4}^{2-}$ e o $\mathrm{C} 3: \mathrm{Na}-\mathrm{Cl}$ ou $\mathrm{Na}-\mathrm{SO}_{4}$. 
Utilizou-se o Programa Aquachem 4.0 Waterloo Hydrogeologics na confecção de Diagramas de Piper e de Stiff. Na espacialização das informações, em distintos planos de informação usou-se o Programa SURFER 8.0 e seus interpoladores matemáticos após avaliação dos variogramas. As informações das captações por poços tubulares foram obtidas dos sítios do Sistema de Informações de Águas Subterrâneas/SIAGAS do Serviço Geológico do Brasil/CPMR/2014. Esse adota o Datum horizontal SAD 69 e o Datum vertical, do Porto de Imbituba, Santa Catarina. Também utilizou as coordenadas obtidas com uso do Global Position System/ GPS, Garmin Etrex. Adotou-se ainda o Sistema de Coordenadas Universal Transversa de Mercator/UTM na especialização dos mapas.

Adotou-se a Resolução do CONAMA №357/2005 para enquadramento dos corpos de água e os preceitos da Resolução CONAMA №396/2008 referente às águas subterrâneas.

Foram estudadas amostras em pó de diferentes materiais geológicos através de diferentes técnicas como a DRX, em amostras não orientadas, em Espectrômetro Shimadzu, Tubo de Cobre, na faixa de 2-72º . Foram testadas amostras de Calcretes, Silcretes, lenhos silicificados, coprólitos (fezes fossilizadas) e ossos répteis fósseis da Formação Santa Maria (Membro Alemoa), buscando-se identificar possíveis barreiras geoquímicas e/ou fontes mineralógicas de $\left(\mathrm{F}^{-}\right)$. Também se realizaram estudos dos argilominerais de amostras orientadas (naturais, calcinadas e com etileno glicol) presentes nas unidades hidroestratigráficas e em amostras de calha coletadas de poços com concentrações anômalas de (F-). Essas amostras pertencem ao acervo da Companhia Rio-grandense de Saneamento/ CORSAN, Superintendência de Recursos Hídricos e Meio Ambiente/SURHMA que perfura poços em áreas urbanas, e do Programa de Açudes e Poços/ PAP/CORSAN da Secretaria de Obras do Estado do RS, que perfura nas áreas rurais.

Foi consultado o banco de dados hidrogeológicos com informações das captações, da CPRM/SIAGAS, do DNPM/SIGHIDRO (águas minerais e fontes hidrotermais). As análises de água coletadas e outros materiais geológicos foram analisados no Laboratório de Química Laquia/Universidade Federal de Santa Maria/ Centro de Ciências Naturais e Exatas/UFSM.

No Laqia foram realizadas análises, através do método de pirohidrólise com uso de pentóxido de Vanádio (Moraes et al., 2003, Silvério da Silva et al. 2002 e Flores et al., 2003), em diferentes materiais geológicos e frações de materiais provenientes de amostras de calha coletadas durante a perfuração de poços tubulares, de captações que continham águas subterrâneas com ( $\left.\mathrm{F}^{-}\right)$ em concentrações anômalas registradas em bancos de dados. Separando-se por sedimentação as frações de argila, com diâmetros de partículas inferior a $2 \mu \mathrm{m}$ e a 1 $\mu \mathrm{m}$ (Silvério da Silva et al., 2002). Testaram-se amostras de fosfato mineral e outras matérias-primas utilizadas na preparação de adubos nitrogenados (NPK) (Brasil, 2000).

Salienta-se que na área do estudo (Figura 2), na (ZA) do SAG é amplamente cultivada com tabaco. Buscandose dessa maneira descartar a hipótese de origem antropogênica para o $\left(\mathrm{F}^{-}\right)$. Procedeu-se um reconhecimento geológico de campo seguido de descrição de amostras em afloramentos. Os estudos foram iniciados no Projeto de cooperação entre a UFSM (Brasil) e as Universidades de Kiel e Frankfurt (Alemanha) Böger und Kowalczyk (1993) para estudos do Mesozóico na Depressão Central.

No Rio Grande do Sul, as pesquisas do Labhidrogeo/ UFSM em águas subterrâneas tiveram início com Silvério da Silva et al. $(2000,2002)$. Nesse período foi estruturado um cadastro de poços tubulares de abastecimento perfurados e/ou operados pela CORSAN/SURHMA, PAP/ SOPS, no SIAGAS/CPRM, no Projeto PSAG (2009a, b, c) e Silvério da Silva et al. (2007). A partir da análise dos resultados, notou-se que em certas fácies arenosas da Formação Rosário do Sul (equivalente a Formação Sanga do Cabral, Figura 2) havia ocorrência de cimento carbonático, o qual poderia ser uma barreira geoquímica para o (F-), modelo proposto na Índia por Jacks et al. (1993, 1999). Também haviam ocorrências de duplas micas (moscovitas e biotitas) (Sartori et al., 1995), sendo que ambas apresentavam-se como minerais alumissilicatos fonte potencial de $\left(\mathrm{F}^{-}\right)$.

Assim a hipótese inicial para o $\left(\mathrm{F}^{-}\right)$proviria da intemperização das biotitas $\left(\mathrm{K}(\mathrm{Mg}, \mathrm{Fe})_{3}(\mathrm{OH}, \mathrm{F})_{2}(\mathrm{Al}, \mathrm{Fe})\right.$ $\left.\mathrm{Si}_{3} \mathrm{O}_{10}\right)$, uma possível fonte de $\left(\mathrm{F}^{-}\right)$, podendo conter até $1,5 \%$ desse elemento. Neste período estavam em execução estudos petrográficos, geoquímicos de amostras de materiais geológicos. Essas análises físico-químicas foram realizadas pelo Laqia, UFSM através do Standard Methods e uso de (ICP/MS e ICP/OS para amostras de águas salobras, enriquecidas em Sódio), e os estudos pela técnica de Difração de raios- $\mathrm{X} / \mathrm{DRX}$ ocorreu no Departamento de Geociências, tanto em amostras em pó não orientadas, bem como em argilominerais amostras orientadas. Esses estudos visam compreender os aspectos paleodeposiconais e paleoclimáticos do meio sedimentar poroso.

Naquela época já existiam pesquisas sobre as ocorrências de ( $\left.\mathrm{F}^{-}\right)$, em captações por poços tubulares da Universidade de Santa Cruz do Sul/UNISC, no Vale do Rio Pardo/RS, pertencente a Região Hidrográfica do Guaíba. Destacando-se estudos de Lobo e Costa (1998), Baccar (1998), Lobo et al. (1999) os quais realizaram análises químicas, registraram as coordenadas das captações, sem terem preocupação com a origem geológica. Portanto, realizaram um monitoramento físico-químico ampliando o conhecimento das captações, contendo ocorrências de $\left(\mathrm{F}^{-}\right)$em escala regional na Bacia Hidrográfica do Rio Pardo e Rio Jacuí.

Isto favoreceu o uso das informações hidrogeológicas constantes no sítio do SIAGAS/CPRM, onde há informações da geologia, hidrogeologia, dos usos das águas, bem como dos parâmetros hidrodinâmicos, 
aos quais puderam ser agregados a SIG e apresentar a espacialização dos resultados. Aplicaram-se métodos geoestatísticos como o SURFER (Santiago, 2011).

Inicialmente no trabalho de Bertazzo (1999) foram incluídas informações de mapeamento geológico realizado em conjunto com a Alemanha (Böger und Kovalczyk, 1993) e (Silvério da Silva et al., 2000). Nessa fase observouse a ocorrência de poços com concentrações anômalas de $\left(\mathrm{F}^{-}\right)$associados aos pacotes de argilas vermelhas da Formação Santa Maria (Aquiclude Alemoa) portadora de ossos de répteis fósseis localmente com fluorapatita e até 31.261,7 ppm de (F-) (Silvério da Silva et al. 2002). Dessa forma, não se descarta a hipótese dessas camadas impermeáveis (Aquiclude Alemoa) servirem como trapp (armadilha), aos gases de HF, possivelmente associados aos diques, ou as soleiras, fases vulcânicas tardias. Frank et al. (2007) propuseram a hipótese de fonte de origem vulcânica para todas as rochas vulcânicas do topo da Bacia Sedimentar do Paraná. Arquela et al. (2003) consideram que os derrames de rochas vulcânicas, podem ser individualizados em corpos tabulóides, denominados por trapps, representando cada episódio de atividade vulcânica do tipo fissural. Também podem ser individualizados diques de diabásio, além de outros corpos intrusivos, cujas composições podem variar de natureza basáltica toleítica a riodacítica. Salienta-se a existência de mais de 20 diques intrusivos seccionando as camadas da Unidade Hidroestratigráfica Alemoa na faixa do estudo, cerca de $250 \mathrm{~km}$ Leste-Oeste devido à sua posição na borda da Bacia do Paraná (Silvério da Silva et al. 2002).

Especializaram-se os resultados analíticos em mapas temáticos as ocorrências anômalas de $\left(\mathrm{F}^{-}\right)$apresentadas por Baccar (1998), pôde-se sobrepor as informações hidrogeológicas do SIAGAS/CPRM. Notou-se que alguns poços tubulares penetravam zonas confinadas SAG/SASG por derrames de rochas vulcânicas e apresentavam $\left(\mathrm{F}^{-}\right)$, (exemplo do Município de Sobradinho, Sinimbu/RS), além dos resultados na (ZA) especialmente nos Municípios de Santa Cruz do Sul, Vera Cruz e Venâncio Aires. Esses municípios apresentam mais de 70\% das ocorrências anômalas de (F-) na (ZA) do SAG Santiago (2011).

Durante a execução dos trabalhos de coletas de águas subterrâneas pela PROINSA/PSAG (2009) para o Consórcio Guarani, foram encontradas cerca de quinze análises de amostras de água a maioria na (ZC) e (ZFC). Porém, apenas duas na (ZA), nos Munícipios de Candelária e Santa Cruz do Sul, região central do Estado do RS (Figura 2). Os resultados analíticos dessas pesquisas serão discutidos na segunda parte desse trabalho.

Santiago (2011) realizou o monitoramento de um poço tubular que apresentava concentrações de (F-) anômalo, de profundidade de $276 \mathrm{~m}$, captando o SAG na (ZA) e/ou das camadas Pré-SAG (os estudos de Geofísica realizados nesse poço não foram conclusivos). A autora realizou coletas no período de Março a Setembro do ano (2010), amostras de águas subterrâneas no Campus da UFSM, bombeando-se água durante 15 minutos, para obter-se amostra representativa sempre de uma mesma porção do aquífero (Appelo and Postma, 2006). Geologicamente esse poço penetra a Formação Santa Maria (ZA) do SAG, podendo penetrar areias brancas, não consolidadas do Subgrupo Estrada Nova (possivelmente Pré-SAG). Estudou as amostras de calha de rochas sedimentares coletadas entre (0-276m) buscando-se identificar minerais de Haletos. Foram testadas frações da matriz sedimentar com peso de $20 \mathrm{~g}$, das amostras de calha, e avaliadas em cada uma delas, as Condutividades Elétricas. Utilizou-se água destilada, buscando-se inferir possíveis zonas em distintas camadas, contendo sais minerais. Os resultados preliminares não foram animadores. Tentava-se encontrar possíveis minerais salinos, na matriz dos sedimentos, realizaram-se evaporação de um litro de água com concentrações anômalas do elemento, buscando caracterizar seu Resíduo Seco.

Buscou-se identificar possíveis flutuações sazonais nas concentrações de alguns parâmetros físico-químicos propostos por Costa et al. (2004). Santiago (2010) e Santiago e Silvério da Silva (2011a) encontraram várias ocorrências anômalas de $\left(\mathrm{F}^{-}\right)$na $(\mathrm{ZA})$ do SAG, em especial nos Municípios de Venâncio Aires, Vera Cruz e Santa Cruz do Sul com valores de concentração, inclusive superiores aos conhecidos para a zona de confinamento do SAG (PSAG/OEA b,c).

Já o poço tubular situado no Campus da UFSM, perfurado com $276 \mathrm{~m}$ penetrando unidades hidroestratigráficas do SAG e possivelmente Pré-SAG, apresenta elevadas concentrações de (F-), $\mathrm{Na}^{+}, \mathrm{Cl}^{-}$e $\mathrm{SO}_{4}^{2-}$ acima do $\mathrm{VMP}$, para consumo humano Santiago (2010). Notou-se uma pequena variabilidade na distribuição de ( $\left.\mathrm{F}^{-}\right)$em uma série de longa duração (18 meses). Outros parâmetros de variabilidade foram: $\mathrm{pH}$, alcalinidade, C.E. e $\mathrm{Mg}^{2+}$ Santiago (2010).

Inicialmente a frequência de amostragem foi semanal e posteriormente as coletas foram mensais visando identificar-se algum efeito de sazonalidade nessa captação (Santiago, 2010).

Esses resultados divergentes, podem ter efeito local das captações, e estão sendo investigados agregando-se outras técnicas como a Geoestatística e Hidroquímica em Cooperação Técnica com o Instituto Superior Técnico da Universidade de Lisboa, Centro de Valorização de Recursos Minerais/IST/CVRM.

\section{Discussões sobre origem do $\left(\mathrm{F}^{-}\right)$em águas subterrâneas}

Andreazzini et al. (1986) citam como fatores controladores da concentração de $\left(\mathrm{F}^{-}\right)$nas águas naturais: a temperatura, $\mathrm{pH}$, presença de íons e colóides complexantes, solubilidade dos minerais que contêm $\left(\mathrm{F}^{-}\right)$, capacidade de troca iônica dos materiais do aquífero $\left(\mathrm{OH}^{-} \rightarrow\left(\mathrm{F}^{-}\right)\right.$, o tamanho e os tipos das formações geológicas percoladas 
pelas águas subterrâneas, e o tempo que essas estiverem em contato com uma formação particular (Ampabire et al., 1997). O (F-) é encontrado nos constituintes de rochas silicáticas, onde a apatita, $\mathrm{Ca}_{10}\left(\mathrm{PO}_{4}\right)_{6} \cdot \mathrm{F}_{2}$, é um dos minerais mais ricos. Este é um componente essencial na fluorita $\left(\mathrm{CaF}_{2}\right)$ e no topázio $\left(\mathrm{Al}_{2} \mathrm{SiO}_{4}(\mathrm{OH}, \mathrm{F})_{2}\right)$. Também pode ser fixado em hidróxissilicatos e hidróxialuminossilicatos complexos, nos quais os íons hidroxilas $\left(\mathrm{OH}^{-}\right)$podem ser substituídos extensivamente por $\left(\mathrm{F}^{-}\right)$, como é o caso dos anfibólios e os minerais do grupo das micas (biotita e moscovita).

Allmann and Koritning apud Wedhephol (1972) discutem a troca-adsorção $\left.\left(\mathrm{F}^{-}\right) / \mathrm{OH}^{-}\right)$em argilominerais, onde as concentrações e o pH das soluções circulantes teriam uma grande influência sobre a lixiviação/adsorção. A troca iônica $\left(\mathrm{OH}^{-} /\left(\mathrm{F}^{-}\right)\right.$em argilominerais favoreceria a troca $\left(\mathrm{Ca}^{2+}\right.$ e $\left.\mathrm{Mg}^{2+} \rightarrow \mathrm{Na}^{+}\right)$, promovendo a progressiva elevação do pH para alcalino (pH 9 - 10,5) (Ampabire, 1997). A diminuição de concentração $\mathrm{Ca}^{2+}$ nas águas favoreceria concentrações mais elevadas em $\left(\mathrm{F}^{-}\right)$.

Silva (1983) identificou um gradiente de direção Oeste-Leste no SAG do Estado de São Paulo, evidenciando um aumento gradativo na temperatura da água e no teor de sais, e nos teores anômalos de $\left(\mathrm{F}^{-}\right)(>1,0 \mathrm{mg} / \mathrm{L})$ teriam sido identificados nas porções francamente confinadas do aquífero, e estariam associados à capacidade da água em dissolver minerais, traços disseminados nas rochas. Essa tendência regional de gradiente de concentração de $\left(\mathrm{F}^{-}\right)$no SAG, não foi confirmada no Rio Grande do Sul (Santiago, 2011). A autora encontrou valores de concentração desse elemento mais elevadas na (ZA) do SAG, centradas em três Municípios: Venâncio Aires, Vera Cruz e Santa Cruz do Sul.

Perroni et al. (1985) ainda no Estado de São Paulo, associavam as altas concentrações em águas subterrâneas a sistemas aquíferos da Bacia do Paraná, destacando-se: o Passa Dois/Tubarão, o Botucatu e o Serra Geral. Esses sistemas aquíferos foram estudados por Iratani e Ezaki (2008) e Hyphólito et al. (2010).

Campos (2004) trabalhando em uma escala regional atribui às estruturas tectônicas o relacionamento com teores elevados de $\left(\mathrm{F}^{-}\right)$em águas subterrâneas da Bacia do Paraná.

IPT (1986), em estudo dos teores (F-) anômalos nos aquíferos Serra Geral e Botucatu, indicavam uma origem associada à circulação de fluidos durante as diversas fases de magmatismo alcalino. Fraga (1992) associou estes teores anômalos de $\left(\mathrm{F}^{-}\right)$nas águas do Aquífero Serra Geral, à contribuições do Aquífero Botucatu, resultando águas $\mathrm{Na}-\mathrm{HCO}_{3}$ de teores entre 0,5 a 2,4 mg/L. As concentrações anômalas de $\left(\mathrm{F}^{-}\right)$estariam relacionadas as águas alcalinas do Aquífero Botucatu.

Kimmelmann et al. (1990) já salientavam ser a origem do $\left(\mathrm{F}^{-}\right)$muito controvertida. A hipótese mais aceita era da lixiviação dos basaltos da Formação Serra Geral. Resultados obtidos no Centro de Pesquisas de Águas Subterrâneas (CEPAS) do Instituto de Geociências da
USP, São Paulo, indicavam uma relação entre o teor deste elemento e a idade das águas. Os sedimentos continentais e marinhos silto-argilosos calcários e areníticos Paleozóicos seriam fonte alternativa, juntamente ao magmatismo alcalino. As características hidroquímicas: $\mathrm{pH}$ alcalino, alta concentração de STD e alcalinidade elevada do sistema, indicando uma tendência de crescimento da concentração $\left(\mathrm{F}^{-}\right)$na direção do confinamento do aquífero, no centro da Bacia do Paraná. Esta tendência foi sugerida por Silva (1983) e aceita por Sracek e Hirata (2002) e PSAG (2009 a,b).

Fraga e Lisboa (1990) sugeriam: (a) comportamento do $\left(\mathrm{F}^{-}\right)$em função dos efeitos de processos intempéricos, geoclimáticos e sedimentológicos (modelo de evolução dos mecanismos de concentração do $\left(\mathrm{F}^{-}\right)$no sistema água-rocha); (b) composição química geral das águas subterrâneas (fatores condicionadores do enriquecimento e tipologia dos fácies hidrogeoquímicos); e, (c) aspectos litoestratigráficos e estruturais da Bacia do Paraná. Sugeriam uma origem sedimentar decorrente dos condicionamentos hidráulico e faciológico do aquífero, um longo tempo de residência das águas. Proveniência de precipitados químicos "crostas salinizadas". Uma origem associada a múltiplas fases de injeção magmática Mesozoica (Magmatismo precoce sob a forma de diques e sills de diabásio; vulcanismo fissural predominantemente basáltico e um vulcanismo tardio, alcalino). Estas injeções propiciariam a cristalização de enormes volumes de fluidos residuais hipótese também sugerida por Kern et al. (2006), para a Bacia do Paraná.

Uma vez que existiam relatos de fluorose dental nas cidades de Venâncio Aires e Santa Cruz do Sul/RS Figura 2. Observando-se uma relação espacial entre as ocorrências de ( $\left.\mathrm{F}^{-}\right)$anômalas em águas subterrâneas e os afloramentos da Formação Santa Maria, Membro Alemoa, com sítios fossilíferos. Esta unidade hidroestratigráfica é constituída por siltitos-argilosos de cor vermelha, constituídos por argilominerais, de estrutura 2:1 (dois tetraedros de $\mathrm{SiO}_{2}$ e um octaedro de $\mathrm{AlO}_{3}$ ) apresentando elevada CTC, esmectitas, ilitas e interestratificado I-S (ilita/escmetita) (Silvério da Silva, 1997 e Drever, 1997). Também ocorrem concreções carbonáticas (caliches, calcretes e toscas). Andreis et al. (1980) Silvério da Silva et al. (1990), Silvério da Silva et al. (2010). Andreis et al. (1980) citavam ocorrências de gipsita, porem devido a urbanização esses afloramentos não foram preservados.

Jacks et al. (1993 e 1999) sugeriam para o Sul da Índia um modelo de concentração de ( $\left.\mathrm{F}^{-}\right)$associado a solos Entisolos pouco desenvolvido pedogeneticamente e Vertisolos de elevado conteúdo em argilas de elevada / CTC. Relatavam que o horizonte $C$, superior continha abundantes níveis de precipitados de carbonatos de cálcio, algumas vezes desenvolvendo um caliche, porém mais frequentemente na forma nodular, e conhecido localmente como Kankar. Relataram a existência em calcretes e dolocretes concentrações até $1 \%$ de $\left(\mathrm{F}^{-}\right)$. Obtiveram para Kankar calcítico concentrações $\left(\mathrm{F}^{-}\right)$entre 
0,01 a 0,1\% e no Kankar dolomítico 0,1 a $1 \%$ atribuídas ao processo de evapotranspiração da água, Handa (1975).

Silvério da Silva et al. (1990, 1997) desenvolveram estudos petrográficos e geoquímicos (ICP/MS). Porém não havia avaliação das concentrações de $\left(\mathrm{F}^{-}\right)$na matriz. Faltavam estudos complementares aos de ICP/MS de concentração de $\left(\mathrm{F}^{-}\right)$em rochas sedimentares pertencentes à Formação Santa Maria. Nos calcretes, em lâminas delgadas utilizou-se a técnica do tingimento Füchtbauer et al. (1988) e observação microscópica. Notou-se que todas as amostras apresentavam carbonatos de cálcio, tipo calcita pura. Seguiu-se a linha mineralógica de Jacks et al. (1993 e 1999), porém os calcretes, os coprólitos apresentaram baixos teores de $\left(\mathrm{F}^{-}\right)$na matriz (Silvério da Silva et al. 2002).

Flores et al. (2003) e Moraes et al. (2003) utilizaram a técnica de pirohidrólise com $\left(\mathrm{V}_{2} \mathrm{O}_{5}\right)$

Testando-se diversos materiais geológicos: calcretes, coprólitos (fezes de répteis fósseis), silcretes. Uma vez que as concreções carbonáticas ora apresentavam-se silicosas, ambas foram estudadas. Durante esta fase dos estudos foram encontradas rosetas do deserto na Formação Santa Maria (Membro Alemoa). Porém os sulfatos, se existentes na fase de paleodeposição, teriam sido substituídos por carbonatos e/ou, por sílica, em função de flutuações do meio sedimentar, poroso, envolvente (Silvério da Silva, 1997).

Jacks et al. (1993 e 1999) propunham uma origem intempérica para explicar as altas concentrações de $\left(\mathrm{F}^{-}\right)$ em águas subterrâneas a partir do intemperismo de gnaisses, granitos, xistos Pré-Cambrianos, contendo minerais de composição aluminossilicáticos hornblenda e micas. Notando-se a existência de duplas micas na Formação Rosário do Sul sugeriu-se como hipótese que o intemperismo destas poderia ser a fonte de origem $\left(\mathrm{F}^{-}\right)$ para as águas subterrâneas de acordo com Almann and Koritinig apud Wedephol, (1972).

Torres-Ruiz et al. (1994) relataram concentrações até $1 \%$ de $\left(\mathrm{F}^{-}\right)$em sepiolitas e paligorsquitas na Espanha. Buscou-se identificar na ZA na Depressão Central diques e/ou corpos que pudessem conter uma mineralogia diferencial dos minerais formadores de rochas.

Deve-se salientar que os sítios fossilíferos aflorantes mais importantes ocorrem nas cidades de Santa Cruz do Sul (Cerro Botucaraí), Candelária (Bexiga), São Pedro do Sul, (Chiniquá) e em Santa Maria (Alemoa/Cerrito) (Böger und Kovalczyk, 1993) e correspondem a (ZA) do SAG Figura 2. Portanto as camadas argilo-siltosas podem influenciar as concentrações desse elemento. Nestas cidades certas captações de águas subterrâneas apresentam elevadas concentrações de $\left(\mathrm{F}^{-}\right)$, na (ZA) do SAG (Silvério da Silva et al. 2000, 2002 e 2008) sugeriram a flúorapatita como uma das possíveis origens do $\left(\mathrm{F}^{-}\right)$, ou ainda uma associação as camadas argilo-siltosas da Unidade Hidroestragráfrica Alemoa do Aquífero Santa Maria contendo argilominerais de elevada CTC Silvério da Silva (1997) e Silvério da Silva et al. (2002).
De acordo com os resultados do projeto PSAG/OEA/ (2009c) "As águas do SAG são, de forma geral, potáveis, com baixa mineralização (indicada pelas condutividades $<1.000 \mu \mathrm{S} / \mathrm{cm}$ ) e baixa velocidade de fluxo. Seus valores de $\mathrm{pH}$ variam muito, desde ácidos 4,5 até básicos 11,0, mas na maioria dos casos, estão próximos da neutralidade. Nota-se que localmente podem existir áreas com maiores concentrações de sulfatos e concentrações de $\left(\mathrm{F}^{-}\right)$superiores aos níveis previstos pelas normas de qualidade da água para consumo humano, sem prévio tratamento (Portaria MS № 2.914/2011) uso doméstico. Áreas com pouca circulação regional de água costumam estar associadas a uma maior salinidade (isso ocorre nas partes centrais da bacia, especialmente nos Estados brasileiros do Paraná, Santa Catarina e Rio Grande do Sul).

Portanto, salienta-se que a área com maior número de ocorrências de $\left(\mathrm{F}^{-}\right)$anômalo em águas subterrâneas Santiago (2011), situa-se na (ZA), PSAG (2009 a, b) constituída por rochas sedimentares clásticas, pertencentes à Depressão Central do Estado do RS, na borda da Bacia do Paraná Figura 2. Estimou-se sua extensão da ordem de $250 \mathrm{~km}$ disposta num eixo de direção Leste - Oeste, e Norte-Sul em torno de 20-40 km. Estas sequências sedimentares clásticas ou terrígenas bordejam os derrames vulcânicos pertencentes à Formação Serra Geral ou se encontram confinadas na (ZC) PSAG (2009).

Giardin e Faccini (2004) já haviam demonstrado a complexidade hidroestratigráfica para a região central do estado do RS zona de afloramento (ZA) do SAG, incluindo o Município de Santa Maria e o Campus da UFSM localizado no Bairro Camobi, junto a Base Aérea.

Informa-se que dos 24 poços de abastecimento no Campus da UFSM que penetram o SAG, em profundidades entre 47 e 128m, apresentam valores baixos de $\left(\mathrm{F}^{-}\right)$, inferiores a 0,2 mg/L (Silvério da Silva, 2002, Dutra, 2005, Marion et al. 2010, Ertel et al. (2012, 2013). Apenas o poço (43000000556 SIAGAS) de 100m apresentava (F), estando em condição desativada, vinha servindo ao monitoramento da Rede RIMAS/CPRM/2012, Löbler et al. (2013) e Löbler (2014 no prelo).

Essa informação torna-se importante uma vez que pesquisas em execução, indicaram ocorrências de ( $\left.\mathrm{F}^{-}\right)$em poços tubulares, na localidade de Faxinal da Palma, Distrito de Santa Maria, com somente 50m de profundidade. Essas captações penetram a Unidade Hidroestratigráfica Santa Maria (Machado, 2005; Machado e Freitas 2005 e Terra, 2014 no prelo). Dessa forma, parece não ser a profundidade do poço um fator controlador, mas sim de origem geológica, as camadas sedimentares penetradas.

A partir do conhecimento de geologia de superfície obtidos ao longo do projeto binacional com a Alemanha (Böger und Kovalczyk, 1993), para a caracterização do Mesozóico do Estado do RS, buscou-se ampliar os conhecimentos na linha de estudos mineralógicos, petrográficos e geoquímicos sobre as concentrações deste elemento, em águas subterrâneas e na interface rocha/água.

As primeiras análises de digestão de amostras de cal- 
cretes realizadas no Laqia/UFSM, da Formação Estrada Nova (Pré-SAG) e da Formação Santa Maria (Membro Alemoa) SAG, foram testados com ácidos concentrados (Silvério da Silva et al., 2000, 2002). Também o uso de hidróxido de sódio para a digestão de amostras em pó (Adelantado et al., 1986). Testou-se ainda a digestão de rochas sedimentares clásticas arenosas e siltosas, uma vez que estas apresentavam em sua matriz duplas micas (Böger und Kowalczyk, 1993 e Sartori et al., 1995). Estas micas podiam ser de origem vulcânica tardia e apresentarem conteúdos de (F-) elevados, hipótese sugerida pelo grupo alemão.

Uma das hipótese de origem de $\left(\mathrm{F}^{-}\right)$para as águas subterrâneas na (ZA) relacionava os processos de intemperismo de minerais aluminossilicatados contendo $\left(\mathrm{F}^{-}\right)$, tais como: biotitas, flogopitas, muscovita, ilitas, feldspatos, seguindo a linha proposta por Jacks et al. (1993, 1999).

Durante o ano de 2001 foram desenvolvidas pesquisas em conjunto com o Centro de Pesquisa de Águas Subterrâneas/CEPAS/USP, UFSM, CORSAN, UFRGS. Os resultados parciais foram apresentados em Silvério da Silva et al. (2002) como novas hipóteses sobre a origem do (F-) em águas subterrâneas quando eram conhecidas 118 ocorrências cadastradas na (ZA) do SAG, no Estado do RS Figura 2.

Nesta fase do conhecimento ainda se tinha dúvidas em relação a origem natural ou antropogênica das concentrações anômalas de ( $\left.\mathrm{F}^{-}\right)$em águas subterrâneas. Visando testar os fertilizantes contendo elementos (NPK), utilizou-se a técnica da hidropirólise (Flores et al., 2003) testando-se rochas fosfáticas, utilizadas como matérias primas em fertilizantes do tipo superfosfatos. Segundo a Normativa №001/2000 do Ministério da Agricultura do Brasil, o Superfosfato Triplo deve conter até o teor máximo $0,7 \%$ de $\left(\mathrm{F}^{-}\right)$, enquanto o fosfato de rocha, deve conter até um teor máximo de $1,5 \%$ de $\left(\mathrm{F}^{-}\right)$.

Estes estudos buscavam identificar a fonte primária do $\left(\mathrm{F}^{-}\right)$, se uma origem geológica ou antrópica. A (ZA) do SAG, Figura 2 é utilizada para implantação de diversas culturas de subsistência, bem como na cultura do tabaco. Localmente ocorrem plantios de eucaliptos e acácia negra (Acacia mearnsii) no (Vale do Rio Taquari). A origem antrópica não era aceita pelo Labhidrogeo, já que no Município de Tabaí, ocorrem concentrações de $\left(\mathrm{F}^{-}\right)$acima do VMP e não havia culturas de subsistência, nem uso de NPK.

Marimon (2006) também testou e descartou a hipótese antrópica para captações na Formação Santa Maria com uso de técnicas isotópicas.

Seguiu-se testando as concentração de $\left(\mathrm{F}^{-}\right)$em diversos materiais geológicos, com uso da técnica da hidropirólise (Silvério da Silva et al., 2002 e Flores et al., 2003). Indicaram que existe grande afinidade entre (F-) e fosfatos. Foram testadas ainda, as concentrações de ( $\left.\mathrm{F}^{-}\right)$ em ossos de répteis fósseis, obtendo-se em uma amostra valores de 31.261,7 ppm. Em análise de DRX constatou-se a ocorrência de fluorapatita. Já que carbonatos e fosfatos, também mostram afinidade, notou-se que poderia haver substituição da fase fosfatada do osso réptil fóssil pelo cimento carbonático displasivo, liberando o $\left(\mathrm{F}^{-}\right)$para o meio. Enquanto no cimento calcítico obteve-se 55,86 ppm, na fração argila infiltrada no osso réptil fóssil que apresentou concentração de 607,6 ppm de (F-).

Foram encontrados afloramentos de diques na (ZA) do SAG, de composição ainda pouco conhecida, próximo dos Municípios de Venâncio Aires e Taquari/RS, Figura 3, discordantes nas camadas vermelhas da Formação Santa Maria (Membro Alemoa), unidade hidroestratigráfica Alemoa (Machado, 2005). Na porção clara (branca) encontrou-se 595,8 ppm (F-), enquanto na marrom 1.403,9 $\mathrm{ppm}$. Distando 0,10 $\mathrm{m}$ do corpo principal encontrou-se teores de 1.083,0 ppm e em $10 \mathrm{~m}$, cerca de 487,7 ppm. Em amostras em pó DRX identificaram-se traços de imogolita e alofana, possíveis produtos de devitrificação de material vulcânico tardio. Estudos em MEV/EDS ainda não se identificaram morfologias características de minerais acessórios e/ou argilominerais contendo significativos teores de $\left(\mathrm{F}^{-}\right)$.

Já, nos calcretes foram identificados microcristais de cerca $1 \mu \mathrm{m}$ de comprimento, de Halita cúbica $(\mathrm{NaCl})$ e Silvita (KCl) (Silvério da Silva, 1997, usando técnicas de MEV/EDS). Ainda foram encontradas nessa unidade concreções carbonáticas (calcretes), com estruturas fibrosas, que poderiam ser originalmente constituídas por cristais de gipsita ou rosetas do deserto (Mayer, 1997).

Uma vez que os carbonatos são cimentos displacivos, esses minerais de depósitos de evaporitos poderiam substituir os cristais originais de gipso $\left(\mathrm{CaSO}_{4} \cdot \mathrm{H}_{2} \mathrm{O}\right)$ assumindo sua forma. Ao microscópio óptico, em amostras em pó em DRX nas análises de MEV não foram identificados registros de minerais de gipso.

Uma vez que haviam sido encontradas duplas micas nos arenitos do Grupo Rosário do Sul Böger und Kovakczyk (1993) e Sartori et al. (1995) e, como suspeitava-se que a origem do (F-) fosse a partir do intemperismo de micas Silvério da Silva et al. (2002). Detalharam-se as frações de uma amostra de calha, de uma captação de poço tubular na Linha Araçá (Município de Restinga Seca) $\mathrm{PAP} / \mathrm{SOPS} / \mathrm{CORSAN}$, contendo 2,2 mg/L (F-). Notou-se existir uma concentração relativa desse elemento, mais elevada nas frações finas, tamanho argila $(<2 \mu \mathrm{m}$ e $<1$ $\mu \mathrm{m})$. Isto sugere o enriquecimento relativo através do processo de troca iônica entre $\left(\mathrm{F}^{-}\right)$e $\left(\mathrm{OH}^{-}\right)$presente na fração argila $(<2 \mu \mathrm{m})$ e/ou em certos argilominerais de estrutura de 2:1 (Almann and Koritinig apud Wedephol, 1972). Salienta-se que estudos de Silvério da Silva (1997) haviam confirmado a presença de argilominerais dos tipos esmectita, ilita e Interestratificado I-S (Ilita-Esmectita) no Grupo Rosário do Sul, Formação Santa Maria. Essa proposta foi adotada por Goffermann (2013) para o Aquífero Rio Bonito (Pré-SAG) e Pirambóia (SAG) (Machado, 2995) e Machado e Freitas (2005).

Silvério da Silva (2000 e 2002) estudaram a matriz 


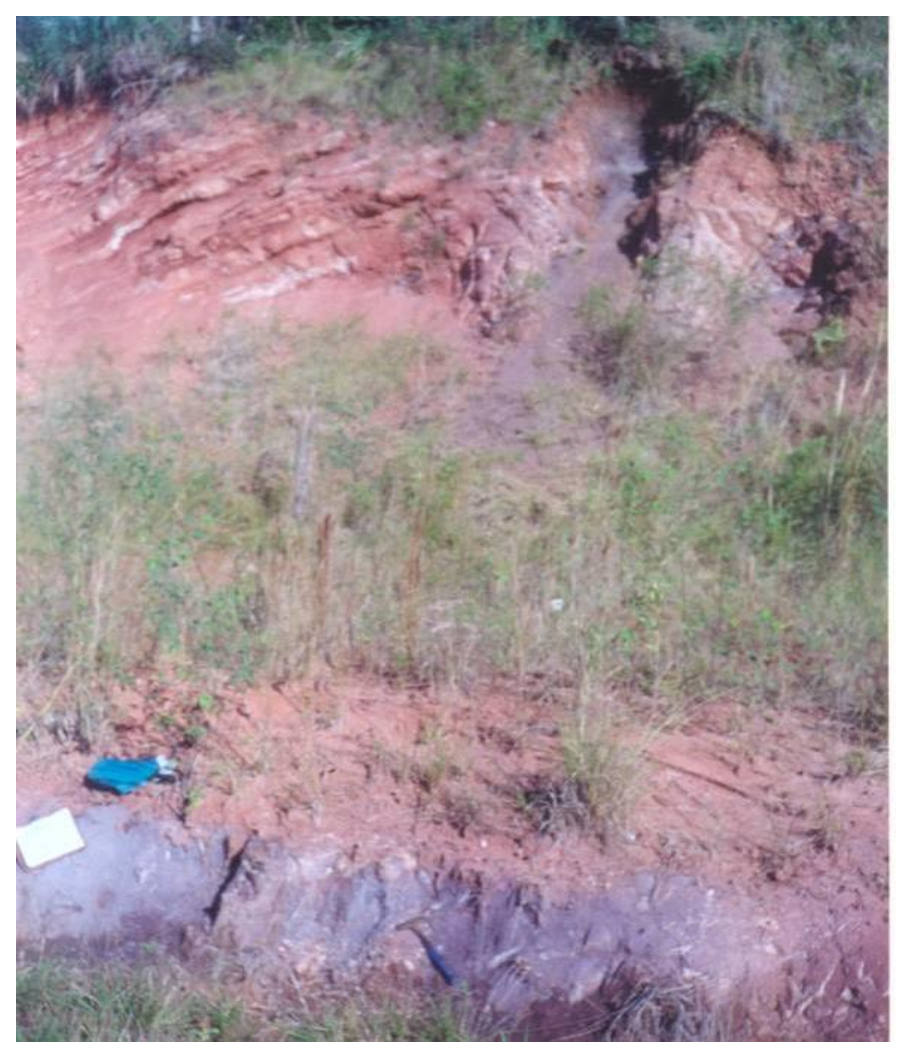

Figura 3- Dique discordante seccionando camadas vermelhas silto-argilosas da Formação Santa Maria, (Aquiclude Alemoa), notar dique de coloração lilás distinta. Município de Venâncio Aires, corte Estrada RST -287 na localidade Arroio Castelhano.

dos diques intrusivos que seccionam as rochas sedimentares na (ZA) do SAG Figura 3. Entre os Municípios de Santa Maria até Município de Tabaí no RS, identificou-se a ocorrência de cerca de 19 diques intrusivos, de composição básica e/ou alcalina. Esses diques estão relacionados as zonas de falhas, direções preferenciais NW e NE, descritas por Machado (2005) e Machado e Freitas (2005) no Mapa Hidrogeológico do Estado do RS. Procurou-se identificar nesse corpos intrusivos (diques ou soleiras) minerais acessórios, diferentes dos minerais aluminossilicatos formadores de rochas vulcânicas básicas e/ou seus produtos de hidrotermalismo em fases tardias. A literatura retrata ocorrências de sepiolitas como produtos de alteração de rochas vulcânicas da Formação Serra Geral (Pós-SAG). Esta hipótese ainda necessita de maiores estudos petrográficos de laboratório. Estudos de materiais geológicos provenientes desses diques em MEV/EDS JEOL na UFRGS, realizados por Silvério da Silva et al. (2002), não apresentaram morfologias e composição específica de minerais contendo concentrações elevadas de $\left(\mathrm{F}^{-}\right)$.

Frank et al. (2007) haviam sugerido como hipótese a contaminação de $\left(\mathrm{F}^{-}\right)$dos aquíferos da Bacia do Paraná, ser derivada da desgaseificação de rochas intrusivas da Formação Serra Geral. Propuseram que o evento hidrotermal, de grande porte e de longa duração forneceria enormes volumes de HF (ácido fluorídrico), o qual teria sido liberado durante as fases de vulcanismo fissural da
Formação Serra Geral, a qual secciona a Formação Santa Maria na forma de diques intrusivos Figura 3. Dessa forma foram desenvolvidas pesquisas associando a litologia de rochas de origem vulcânica com concentrações de (F-) em: Abreu (1981), Lisboa e Menegotto (1999), Nanni (2006), Nanni (2008), Mocellin (2009), Nanni et al. (2013), Mancuso et al. (2013) e Mancuso et al. (2014).

A partir dos resultados obtidos no projeto №10 Fundo das Universidades OEA/PSAG/GEF, Silvério da Silva et al. (2005) e Silvério da Silva et al. (2006), observaram ausência de águas fluoretadas na região da fronteira com o Uruguai. Esses autores estudaram amostras de águas, sendo os politipos predominantemente $\mathrm{Ca}-\mathrm{Mg}-\mathrm{HCO}_{3^{\prime}}$ de baixa mineralização (os resultados físico-químicos serão apresentados e discutidos no segundo artigo).

Os resultados do PSAG/OEA/PEA (2009c) sugerem que "o $\left(\mathrm{F}^{-}\right)$está associado a águas mais salinas, termais e com relação $\mathrm{rNa} / \mathrm{rCl}$ (meq/L), mais próximas a 1 , o que sugere que a fonte de ( $\left.\mathrm{F}^{-}\right)$(pelo menos a principal) estar nas formações salinas do Pré-SAG".

Salienta-se que o uso de razões iônicas pode ser importante na avaliação da possível origem do $\left(\mathrm{F}^{-}\right)$, se hidrotermal, de fontes de águas salinas e/ou de evaporitos (depósitos de sais), bem como uma evolução intempérica, conforme sugerem pesquisas de Vengosh; Pankratov (1998), Panagoulias e Silva Filho (2006), Alcalá y Custódio (2008), Manzano y Guimaraens (PSAG, 2009c).

Nesta parte da pesquisa serão apresentados alguns 
resultados novos das ocorrências de $\left(\mathrm{F}^{-}\right)$em águas subterrâneas na porção confinada do SAG (ZC e ZFC) no Noroeste do Estado do Rio Grande do Sul e Sudoeste do Estado de Santa Catarina.

Zanatta e Coitinho (2002) relataram que a Companhia Catarinense de Saneamento/CASAN vinha obtendo sucesso na captação profunda de águas subterrâneas na porção confinada do SAG no meio-Oeste e Oeste.

Zanatta (2011, informação verbal) relatou a existência de novas captações de águas subterrâneas nos Municípios de Maravilha, São Lourenço do Oeste, Presidente Castello Branco, Seara, São Miguel do Oeste. Poços tubulares em operação, portanto sem concentrações anômalas de (F-).

Uma das captações da Companhia Catarinense de Saneamento/CASAN no Município de Peritiba, penetra o SASG e o SAG, apresenta ( $\left.\mathrm{F}^{-}\right)$anômalo e não apresenta termalidade. Essa captação somente é utilizada em períodos de maiores necessidades humanas, ela sofre mistura com águas superficiais, para adequar-se ao padrão de potabilidade.

Freitas et al. (2003) no Projeto Oeste de Santa Catarina/ PROESC notaram a existência de variabilidade nas cotas dos arenitos da Formação Botucatu/SAG em posição de confinamento. Scheibe e Hirata (2008) divulgaram uma revisão do contexto tectônico dos Sistemas SAG e SASG em Santa Catarina Nanni (2006) e em Nanni et al. (2008, 2013) propuseram "O (F-) em águas do Sistema Aquífero Serra Geral no Estado do RS: origem e condicionamento geológico" e indicam a similaridade entre as composições de águas encontradas no SASG e no SAG, o que somente seria possível pela comunicação hidráulica, através de grandes fraturas existentes nos basaltos, com extensão vertical da ordem de $400-500 \mathrm{~m}$, as quais permitiriam a ascensão de águas de aquíferos sotopostos ao SASG, constituindo, assim, águas mineralizadas, oriundas de mistura. Esta proposição, já era aceita por Freitas et al. (2003) para o Estado de Santa Catarina. Seguindo essa proposição Machado e Freitas (2005) adotaram o mesmo modelo para as rochas vulcânicas pertencentes ao SASG, no Estado do RS.

Até o presente momento ainda são poucas as informações existentes relativas às cotas do topo dos arenitos, abaixo do SASG. Sabe-se que são variáveis, bem como a espessura das camadas, possivelmente devido ao paleoambiente deposicional, bem como aos efeitos de tectônica rúptil. $\mathrm{Na}(\mathrm{ZC})$ muitas vezes são encontradas camadas de arenitos denominados interderrames. São camadas descontínuas e de espessura variável, exemplos ocorrem nos Municípios de Toropi, Silveira Martins, Encantado, Quaraí no RS. Por outro lado, no Estado de SC, tem-se conhecimento de pequenas espessuras de arenitos do SAG, no Município de Itá, chegando a inexistir em São João do Oeste Freitas (2003). Novas perfurações em poços profundos poderão confirmar a proposta do PSAG/ OEA/PEA (2009) ou ainda aperfeiçoá-la. Estudos atuais (Sheibe et al., no prelo) deverão sugerir para o Bloco Sul do SAG ampliação das zonas de gestão, tendo em vista suas peculiaridades litológicas e estruturais.

Na porção Nordeste do Estado do RS, na (ZFC) do SAG, a CORSAN realizou uma perfuração profunda no Município de Erechim, captando águas contendo vários elementos químicos $\left(\mathrm{Na}^{+}, \mathrm{Cl}^{-}, \mathrm{SO}_{4}^{2-}, \mathrm{F}^{-}\right)$acima do VMP para consumo humano. Salienta-se que essas águas, sofrem misturas com águas superficiais como citado no Município de Peritiba/SC, para enquadramento nos valores de potabilidade. Silvério da Silva et al. (2008) citam altas concentrações de $\left(\mathrm{F}^{-}\right)$em balneários hidrotermais do Estado do RS, Municípios de Três Arroios e Nova Prata na (ZFC).

Recentemente o Laboratório de Engenharia Ambiental/UFSM/FW Mancuso et al. (2013) e Mancuso et al. (2014) identificaram a ocorrência de várias captações por poços tubulares contendo concentrações de (F-) anômalo. Essas captações são de diferentes profundidades e penetram o SASG na (ZFC) até $548 \mathrm{~m}$ de profundidade.

Já Schroeder et al. (2013), observaram, a partir da base de dados da Vigilância Sanitária Regional, a ocorrência de $\left(\mathrm{F}^{-}\right)$em concentrações superiores a 1,5 mg/L, nos sistemas de distribuição de água por poços de abastecimento público (Sistema de Abastecimento Individual e Solução Alternativa Coletiva - SAI/SAC), na Formação Serra Geral, no Noroeste do Estado do RS. Foram encontradas concentrações de $\left(\mathrm{F}^{-}\right)$entre 1,5 até $3,6 \mathrm{mg} / \mathrm{L}$, as quais foram identificadas em, pelo menos, uma das amostras coletada entre os anos de 2010, e 2014. Os municípios com ocorrências anômalas foram: Rio do Índios, Alpestre, Caiçara, Pinhal, Pinheirinho do Vale, Planalto, Três Passos, Vicente Dutra, Nonoai, Ametista do Sul, Frederico Westphalen, Cristal do Sul, Vista Alegre, Iraí e Liberato Salzano, ilustrados na Figura 4.

Deve-se salientar que vários desses poços são comunitários ou pertencentes a Sociedades Hídricas e utilizados para abastecimento rural na dessedentação humana e animal. Muitas dessas captações já foram desativadas ou lacradas pelas Vigilâncias Sanitárias Municipais. Exemplos na (ZA) do SAG, Municípios de Vera Cruz e Venâncio Aires. Tanto a CASAN quanto a CORSAN, companhias de abastecimento, quando captam poços tubulares com elementos químicos acima do VMP para consumo humano, adequam sua composição antes de distribuírem para a população, Decreto Federal N. 5.440/2005. Porém, deve-se salientar que municípios menores, abastecidos pelas Prefeituras Municipais ou empresas em regime de comodato, nem sempre adequam às normas de potabilidade, ex. na (ZA) Município de São João do Polêsine (Terra no prelo).

Salienta-se ainda inexistirem relatos de ocorrências de fluorose dental comprovados na região Noroeste do Estado do RS e Sudoeste de SC. Merece registro, várias águas minerais apresentam $\left(\mathrm{F}^{-}\right)$acima do VMP para consumo humano, mas continuam sendo envasadas. Normalmente os consumidores dessas águas não observam as concentrações dos elementos químicos apresentados nos rótulos, ou ainda desconhecem os efeitos que possam 


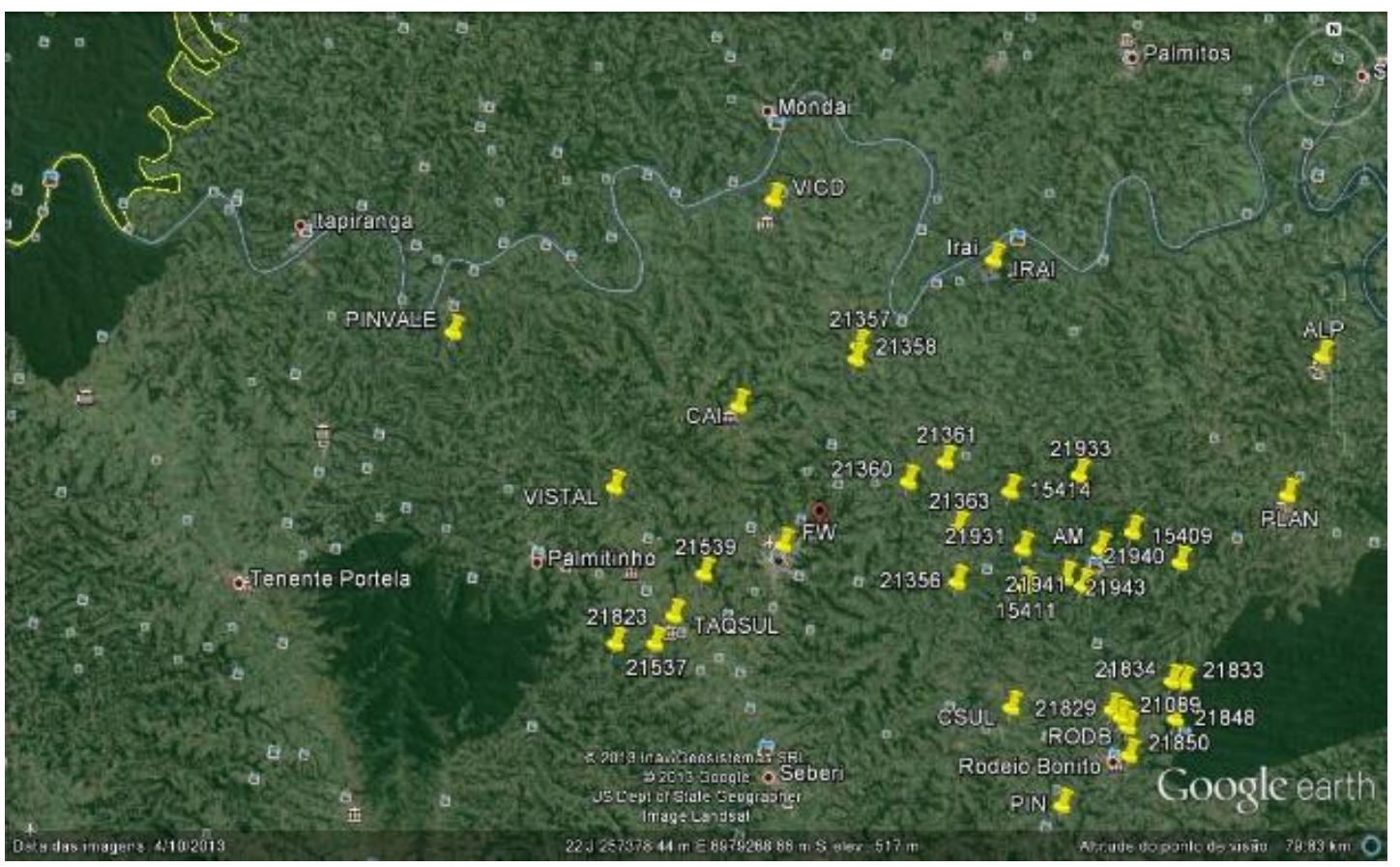

Figura 4- Espacialização das captações com ocorrências de (F-) anômalo no Noroeste do Estado do RS. Fonte: Mancuso et al. (2013), Mancuso et al. (2014).

causar no organismo humano. Maiores informações estão disponíveis em Silvério da Silva et al. (2011b) e no sítio SIGHIDRO/DNPM, ex. Município de Iraí/RS.

Pode-se dizer de uma forma geral, que os estudos realizados por Flores (2003), Moraes (2003) e Marimon (2006) descartaram a origem antrópica do $\left(\mathrm{F}^{-}\right)$a partir da aplicação de fertilizantes minerais a base de NPK para a (ZA) do SAG no Estado do RS.

Marimom (2006) concluiu que os teores elevados de $\left(\mathrm{F}^{-}\right)$no Aquífero Santa Maria, pertencente a (ZA) do $S A G$, resultam das interações água-rocha associadas à circulação de fluídos em estruturas tectônicas regionais levando a mistura de águas subterrâneas de aquíferos mais profundos Pré-SAG. Esta hipótese é validada nesta pesquisa, pelo menos para a área central do estado.

Acredita-se que esses elementos químicos (NPK) dos fertilizantes, contribuem muito pouco para as concentrações anômalas de $\left(\mathrm{F}^{-}\right)$nas águas subterrâneas das (ZA, ZC e ZFC) no Bloco Sul do SAG. Essa ideia também vale para outros aquíferos que estejam relacionados a outros reservatórios. A origem geogênica natural, a partir de minerais dissolvidos em águas subterrâneas parece ser a mais aceita. Porém, sua origem ainda permanece polêmica, necessitando maiores estudos, em distintas escalas, regional, local e pontual. Uma vez que um aquífero ou um sistema aquífero ultrapassa a área de um Município, de uma Bacia Hidrográfica e pode ter dimensão de vários estados. O exemplo seria o SAG, que abrange parte de oito estados brasileiros, e ainda ser transfronteiriço com o Uruguai, a Argentina e o Paraguai. A origem hidrotermal e/ou intempérica necessita de ampliação dos estudos, utilizando-se técnicas integradas de cartografia hidrogeológica, isotópica, hidroquímica em especial as razões iônicas $\mathrm{Cl} / \mathrm{F}$ e Br/F Vengosh and Pankratov (1998), Alcalá y Custódio (2008), Manzano y Guimaraens (PSAG, 2009c). O uso de modernas técnicas analíticas em estudos integrando ICP/MS, e/ou ICP/OS para as águas salobras contendo mais de $1.000 \mathrm{mg} / \mathrm{L}$ de sais totais dissolvidos Resolução CONAMA № 357/2005, Resolução CONAMA № 386/2008.

Deve-se conhecer melhor a importância das estruturas tectônicas na litoestratigrafia das camadas sedimentares que podem estar comunicando aquíferos com distintas composições físico-químicas, inclusive as surgências devido a pressões piezométricas.

Giardin e Faccini (2004) já haviam mostrado a complexidade hidroestratigráfica da Formação Santa Maria na porção central do Estado do RS. Essa unidade hidroestratigráfica também foi discutida por Soares et al. (2008b), com ocorrência restrita ao bloco central do estado RS, Sistema de Falhas (SFJM/SFTAP/SFDC) Machado (2005) e Machado e Freitas (2005).

A fase atual dos estudos indicaram tanto para a (ZA), quanto (ZFC) no Estado do RS ocorrências anômalas de $\left(\mathrm{F}^{-}\right)$mais detalhados do que aqueles apresentados pelo Consórcio Guarani no PSAG (2009 a, b, c). Na (ZA) Santiago (2011) relatou concentrações anômalas centradas em três Municípios (Vera Cruz, Santa Cruz do Sul e Venâncio Aires) muito superiores aqueles das (ZC e ZFC). Sua origem pode ser oriunda dessas zonas confinadas com fluxos direcionados (ZA) que serviria de zona de descarga, na porção central do Estado do RS. Os únicos estudos usando técnicas isotópicas foram realizados por Marimon (2006) em escala pontual na 
Bacia Hidrográfica do Rio Pardo. Sugere-se a realização de estudos isotópicos, integrando-se distintas técnicas, inclusive Geofísicas aos Modelos Conceituais e de fluxos propostos.

A ampliação do cadastro dos poços realizados pela CPRM/SIAGAS, bem como o aumento dos processos de outorga de uso dos recursos hídricos subterrâneos, contendo detalhados perfis geológicos, análises físicoquímicas e bacteriológicas, ensaios de bombeamento (24 h de duração), atualização das medições de níveis das águas, instalação de tubos laterais, para introdução de sondas multiparâmetros, Decreto Estadual N. 42.027/2002. Esses resultados trarão novos aportes aos conhecimentos, os quais contribuirão na compreensão da evolução hidroquímica e na gestão do SAG.

Deve-se salientar que as retiradas excessivas de um aquífero poderão causar misturas com águas salobras sódicas, não potáveis e ainda aquelas que apresentem teores de (F-) anômalos, a partir de captações de aquíferos Pré-SAG. Outra possibilidade são as surgências que também necessitam investigação na (ZA) do SAG (Terra no prelo).

Os processos de troca $\mathrm{Ca}^{2+}$ pôr $\mathrm{Na}^{+}$em águas alcalinas, parecem facilitar as trocas de $\left(\mathrm{OH}^{-}\right)$por $\left(\mathrm{F}^{-}\right)$, uma vez que esses elementos apresentam a mesma carga elétrica e seus raios iônicos são semelhantes, em argilominerais que apresentem elevada CTC (família das esmectitas, ilitas, cloritas) ficando fracamente sorvidos, ou ainda, associados a outros complexos de troca como óxido-hidróxidos. Essa proposta também foi seguida em Goffermann (2013) para explicar as concentrações anômalas de $\left(\mathrm{F}^{-}\right)$ nos Aquíferos Permianos (Rio Bonito), pertencente ao Grupo Passa Dois (CPRM, 2008), Pré-SAG, na região do Município de São Gabriel (RS), zona de transição entre o cristalino fissural e os aquíferos porosos.

Dessa forma, é importante que os modelos conceituais e de fluxos, utilizando técnicas isotópicas também considerem a mineralogia potencialmente capaz de fornecer (F-) para as águas.

De acordo com RIMAS/CPRM (2012) na zona aflorante (ZA) do SAG, no aquífero livre, predominam águas bicarbonatadas cálcicas, fracamente mineralizadas e com $\mathrm{pH}$ ácido. Da área de recarga até as regiões de forte confinamento (ZFC), as concentrações passam de 100 a 200 mg/L de Sólidos Totais Dissolvidos/ STD para mais de $1.000 \mathrm{mg} / \mathrm{L}$. De Oeste para Leste aumentam os teores de $\mathrm{Na}$, do mesmo modo que em profundidade. Os teores excessivos de fluoretos podem ocorrer na porção confinada em profundidade, devido a fenômenos tectônicos, Machado e Freitas (2005), Nanni (2008) e Nanni et al. (2013).

Wang et al. (2009) dizem que a maioria das águas subterrâneas com concentrações elevadas de Arsênio (As) e ( $\left.\mathrm{F}^{-}\right)$são águas sódicas.

Por outro lado, informa-se que estudos do Consórcio Guarani (PSAG/200b) mostraram águas, sódicas, cloretadas com ocorrências de $\left(\mathrm{F}^{-}\right)$anômalas e raras contendo
Arsênio. Silva (1983), IPT/1986, Mocellin (2009) e vários outros concordam que a composição química das águas do SAG é muito variável, principalmente nas zonas confinadas. Seja por efeitos de variações faciológicas, seja por influência de misturas induzidas por fraturas. De acordo com Sracek e Hirata (2002), existem evoluções de águas $\mathrm{Ca}^{-} \mathrm{HCO}_{3^{\prime}}$ na (ZA) e (ZC), para águas de caráter $\mathrm{Na}-\mathrm{HCO}_{3}$, com aumento das concentrações de $\mathrm{Cl}^{-}$e $\mathrm{SO}_{4}^{2-}$ em profundidade, na (ZFC). Esta mudança na composição química da água dá-se através da diminuição da concentração do $\mathrm{Ca}^{2+}$ por intercâmbio com o $\mathrm{Na}^{+}$, originada pela dissolução dos carbonatos, fazendo com que as águas evoluam para $\mathrm{Na}-\mathrm{HCO}_{3}$. Parte do $\mathrm{Na}^{+}$nesta reação de troca proviria, provavelmente dos aquíferos Pré-SAG, e a adição de $\mathrm{Cl}^{-}$e $\mathrm{SO}_{4}^{2-}$, estaria relacionada à dissolução de evaporitos contendo $\mathrm{NaCl}$, Kern et al. (2008) e mirabilita $\left(\mathrm{Na}_{2} \mathrm{SO}_{4} \cdot 10 \mathrm{H}_{2} \mathrm{O}\right)$, ou gipso $\left(\mathrm{CaSO}_{4} \cdot 2 \mathrm{H}_{2} \mathrm{O}\right)$, e associada à difusão de produtos de dissolução da Formação Pirambóia (Mocellin, 2009). Essas são hipóteses mineralógicas que necessitam maior investigação, para serem validadas ou descartadas.

Dentre os avanços ao conhecimento do $\left(\mathrm{F}^{-}\right)$em águas subterrâneas no Estado do RS e no Uruguai, merece ser registrado, o reconhecimento por parte do Projeto PSAG/ PEA/2009, das atividades dos Grupos Labhidrogeo/Laqia/UFSM e da UdelaR/Uruguai, nas pesquisas sobre a origem do $\left(\mathrm{F}^{-}\right)$em certas camadas do SAG. Também se menciona o caso da Universidade Federal de Santa Maria (UFSM), com forte presença acadêmica geocientífica na região central e sul do Estado do Rio Grande do Sul, no Brasil. No entanto, até o momento, eram incipientes seus antecedentes em pesquisa hidrogeológica. A aproximação com o grupo da UdelaR, de forte capacidade em hidrogeologia quantitativa, permitiu fortalecer o grupo de pesquisa nos temas de água subterrânea. Hoje, a UFSM já conta com um grupo regular de estudantes e pesquisadores que vem desenvolvendo estudos relacionados ao SAG e se gabaritou para apoiar demandas específicas dos municípios na região incluindo temas relacionados ao excesso de $\left(\mathrm{F}^{-}\right)$em certos estratos do SAG.

Ainda se devem destacar avanços no conhecimento do ( $\left.\mathrm{F}^{-}\right)$em águas subterrâneas através dos aportes em pesquisa das Universidades em dissertações e teses de doutoramento, já desenvolvidas na região do Vale do Rio Pardo, pela UNISC/Santa Cruz do Sul. Acrescenta-se Instituto de Geociências da UFRGS, usando técnicas isotópicas, tanto na região central, quanto na região Oeste do Estado do Rio Grande do Sul. Acrescentam-se ainda os estudos realizados pelo Grupo de Engenharia Ambiental, CESNORS da UFSM, na região de Frederico Westhphalen, Ametista do Sul e Cristal do Sul, trabalhando junto ao cadastro de poços SIAGAS/ CPRM e Coordenadoria Regional de Saúde 28aㅡ CRE e Vigilâncias Sanitárias Municipais. A UFSC, através da Rede Guarani Serra Geral e do Comitê de Bacias do Rio Jacutinga que também estão avaliando esse tema. Merece ser destacada a importância do Serviço Geológico 
Nacional/CPRM através do SIAGAS e da Rede RIMAS (2012) vem favorecendo estudos integrados, beneficiando as comunidades acadêmicas com informações de águas subterrâneas importante para pesquisas bem como trazendo benefícios sociais.

Esse tema polêmico, ainda há de ser mais estudado, existindo espaço para estudos multidisciplinares como os de Geologia Médica e Hidroquímica aplicados à Saúde Pública.

Merece ser registrado que em estudos iniciais de Santiago (2011), na (ZA) do SAG indicavam que poços perfurados até cerca se $100 \mathrm{~m}$, não apresentam concentrações anômalas de $\left(\mathrm{F}^{-}\right)$. Deve-se salientar que semelhante fato, ocorria no Campus da UFSM em Santa Maria, onde poços com até $128 \mathrm{~m}$, apresentam (F-) abaixo do VMP, para consumo humano. Já no Município de Candelária apresentaram três ocorrências anômalas, enquanto nos Municípios de Santa Maria, São João do Polêsine, Restinga Seca, Faxinal do Soturno e em Pântano Grande apresentaram duas ocorrências. Observou-se apenas uma ocorrência nos Municípios: Rosário do Sul, Dona Francisca, Rio Pardo, Vale Verde, Bom Retiro do Sul, Taquari e Tabaí (Santiago 2010), (Figura 2).

Os estudos na zona confinada (ZC e ZFC) nos estados do RS, SC, PR e SP parecem estar associadas às fraturas profundas (Campos, 2005) e/ou misturas de águas oriundas do SAG e SASG Nanni (2006) e Nanni et al. (2013). Vários pesquisadores concordam com essa hipótese. Sugere-se o uso de estudos das razões molares entre os elementos $\mathrm{Cl} / \mathrm{Br}, \mathrm{Cl} / \mathrm{F}$ buscando-se identificar fontes hidrotermais, ou minerais salinos de evaporitos ou intempéricos, bem como os Elementos Terras Raras, buscando-se identificar distintas assinaturas.

\section{Conclusões}

A ampla revisão da literatura apresentada servirá de suporte a novas investigações no país sobre as ocorrências anômalas de (F-) em águas subterrâneas.

Os resultados de Santiago (2011) iniciaram a ocorrência de $\left(\mathrm{F}^{-}\right)$anômalo na (ZA) do SAG, cerca de $75 \%$ das ocorrências desse elemento, estiveram centradas em três municípios (Venâncio Aires, Santa Cruz do Sul e Vera Cruz) Figura 2, do SAG constituindo uma possível área de descarga a partir das zonas confinadas. Apresentaram-se outras ocorrências de ( $\left.\mathrm{F}^{-}\right)$anômalas em rochas vulcânicas, da Formação Serra Geral/SASG na região Noroeste do Estado do RS e Sudoeste de SC, muitas dessas captações são de águas frias.

Os valores elevados de ( $\left.\mathrm{F}^{-}\right)$na $(\mathrm{ZA})$ do $\mathrm{SAG}$ podem representar uma linha de fluxo regional, indicando uma possível zona de descarga, na (ZA) e/ou misturas de águas de formações Pré-SAG associadas aos diques intrusivos, que resultariam na descontinuidade de camadas sedimentares, constituindo uma barreira impermeável, bem como um aumento no tempo de transporte/residência, resultando um enriquecimento em $\mathrm{F}^{-}, \mathrm{Na}^{+}, \mathrm{Cl}^{-}$e $\mathrm{SO}_{4}^{2-}$. Essa hipótese deve ser melhor estudada.

Buscar-se-á auxílio em técnicas analíticas de ICP/MS e ICP/OS as assinaturas de outros elementos químicos, tais como: o Boro, o Estrôncio, o Lítio, os Elementos Terras Raras, assinalar-se tendências nas concentrações anômalas de ( $\left.\mathrm{F}^{-}\right)$em águas subterrâneas. Os estudos integrados de microscopia óptica, em MEV, DRX de argilominerais e mineralogia total em pó, aliadas as técnicas isotópicas e de fluxo subterrâneo trarão novos conhecimentos.

Sugere-se associar às ocorrências de fluorose dental as captações de águas de poços tubulares, escavados com concentrações de ( $\left.\mathrm{F}^{-}\right)$anômalas. O uso dos politipos de águas e de mapas temáticos ajudam a espacializar as informações em alvos, onde os estudos devem ser ampliados em escala pontual, bem como os métodos estatísticos (Mancuso et al. 2014).

\section{Agradecimentos}

a CAPES Bolsa de Estágio Sênior BEX 3954/13-7, Instituto Superior Técnico/IST, Centro de Valorização de Recursos Minerais, Lisboa, Portugal. Ao Projeto PSAG/ OEA/GEF Consórcio Guarani. A CORSAN/SURHMA/ PAP/SOPS/CPRM Serviço Geológico do Brasil/CASAN/ FAPERGS/CAPES/ UFSM/ Vigilâncias Sanitárias Municipais/ Membros do Comitê da Bacia do Rio Jacutinga/ SC/ Rede Guarani/Serra Geral, Brasil e ao IST/CVRM/ Portugal.

\section{Referências}

Abreu, I.B. Estudo hidrogeoquímico das águas subterrâneas do Estado do RS. Dissertação de mestrado, IPH, UFRGS 1981, Porto Alegre, 69 p.

Arquela, E.; França,V.; Celligoi, A. Geologia, Geomorfologia e Disponibilidade Hídrica Subterrânea na Bacia Hidrográfica do Ribeirão Jacutinga. Geografia - Londrina - V. 12 - N. 2 JUL./DEZ.2003. Disponível em http://www.uel. br/revistas/uel/index.php/geografia. Visitado em 20/01/2014.

Adelantado, G. J. V.; Martinez, V.P., Moreno, A. C.; Reig, F. B. Spectrophotometric determination of fluoride in fluoride-bearing minerals after decomposition by fusion with sodium hydroxide. Talanta, 1986. vol. 32, №3, pp.224-226, 1986.

Alcalá, F.J.; Custódio, E. Using the $\mathrm{Cl} / \mathrm{Br}$ ratio as a tracer to identify the origin of salinity in aquifers in Spain and Portugal. Journal of Hydrology (2008) 359, 189-207. Available at www.sciencedirect.com. 
Visited January 10, 2014.

Allmann, R.; Koritining, S. Fluorine. In: WEDEPOHL, K.H. (Ed.). Handbook of Geochemistry. Berlin: Springer-Verlag. 1972. Cap. 9, 66 p.

Ampabire, W.B.; Boyle, E.R.; Michel, F.A. Geochemistry, genesis and health implications of fluoriferous groundwaters in the upper regions of Ghana. Environmental Geology. 1997. v. 33, n.1,p.13-24.

Andreis, R. R.; Bossi, G.E.; Montardo, D.K. O Grupo Rosário do Sul (Triássico) no Rio Grande do Sul. In: Congresso Brasileiro de Geologia, 31, Camboriú (SC), Anais. Camboriú, SBG. 1980, v.2, p.659-673.

Appelo, C.A. J. and Postma, D. Geochemistry, groundwater and pollution. 2nd. Edition. A.A. Balkema Publhishers London, New York, Philadelphia/Singapore. 2006, p.649.

Araujo, L.M.; Franca, A.B.; Potter P. Hydrogeology of the Mercosul aquifer system in the Paraná and Chaco-Paraná Basins, South America, and comparison with Navajo-Nugget aquifer system, USA. Hydrogeology Journal. 1999. 7: 317-336.

Asheley, R.P. and Burley, M.J. Controls on the occurrence of fluoride in groundwater in the Rift Valey of Ethiopia. In; Nash, H. Groundwater Quality 17th Special Report, 1995. p.45-54.

Baccar, N. M. Estudo da qualidade da água de poços artesianos da região do Vale do Rio Pardo, com destaque para a concentração de fluoretos, RS, Brasil. Santa Cruz do Sul, UNISC, Trabalho final de graduação em química. 1998. 130f, il.

Banks, D.; Reimann, C.; Skarphagen, H. The comparative hydrochemistry of two granitic island aquifers: The Isles of Scilly, UK and the Hvaler Islands, Norway. The Science of the Total Environment, 1998. v. 209, p.169-183.

Barberena, M. C. Bioestratigrafia da Formação Santa Maria: utilização de Cenozonas como horizontes de correlação. Ciência Hoje, Rio de Janeiro, 1987. v. 6, n. 34, p. 44-50, 1987.

Bell, F.G. Environmental geology: principles and practice. [Oxford]: Blackwell Science, 1998. 594 p.

Bertazzo, V. M. Estudo da qualidade da água de poços utilizados como fontes de abastecimento no Município de Santa Maria, RS. Monografia de Graduação UNISC, 1999. 81p.
Brasil, Serviço Geológico Nacional/CPRM/Sistema de Informações de Águas Subterrâneas. Disponível em: http://www.cprm.gov.br./SIAGAS.

Brasil, Serviço Geológico Nacional/CPRM/ RIMAS- Disponível em: http://www.cprm.gov. br/publique/media/Volume16_Sistema\%20 Aqu\%C3\%ADfero\%20Guarani_RS.pdf. Visitada em 14/01/2014. Volume 16-SAG.

Brasil, Departamento da Produção Mineral/DNPM/ Banco de dados de Fontes Hidrominerais do Brasil. SIGHIDRO. Disponível em: http://www.dnpm. gov.br/sighidro.

Brasil, Ministério do Meio Ambiente/MMA. Resolução CONAMA no357/2004. Dispõe sobre enquadramento de corpos de água. Disponível: <http://www.mma.gov.br/port/conama/res/res05/ res35705.pdf. Visitada em 10/08/2011>. Acesso em: 12 de agosto de 2011.

Brasil, Ministério do Meio Ambiente/MMA. Resolução CONAMA № 396/2008 - “Dispõe sobre a classificação e diretrizes ambientais para o enquadramento das águas subterrâneas e dá outras providências." - Data da legislação: 03/04/2008 Publicação DOU № 66, de 07/04/2008, p. 66-68.

Brasil, Portaria Ministério da Saúde, Brasil № 2.914/2011. Disponível em: http://bvsms.saude.gov. br/bvs/saudelegis/gm/2011/prt2914_12_12_2011. html. Visitada 01/05/2013.

Brasil, Normativa №001/2000 do Ministério da Agricultura o Superfosfato Triplo.Brasil, Decreto N. ${ }^{\circ}$ 5.440/04/05/2005.

Estabelece definições e procedimentos sobre o controle de qualidade da água de sistemas de abastecimento e institui mecanismos e instrumentos para divulgação de informação ao consumidor sobre a qualidade da água para consumo humano. Disponível em: http://www. planalto.gov.br/ccivil_03/_Ato2004-2006/2005/ Decreto/D5440.htm

Brézilon, M. Dictionnaire de la Pre Histoire. Librairie Larousse. Tradução para a língua Portuguesa, Edições 70 Ltda. Tradução Maria Gabriela de Bragança. 1969. Lisboa. p. 297.

Böger, H.; Kowalczyk, G. Stratigraphische, Sedimentologische und Paläoökologische Untersuchungen Im Mesozoikum Der Depressão Periférica in Rio Grande do Sul, Brasilien, BerichteReports, Geol.-Paläont. Inst. Univ. Kiel. Nr. 63, S. 
72., 4 Abb., 9 Tab., Kiel, (Juli). 1993.

Caetano-Chang M.R. Formação Pirambóia no LesteCentro Estado de São Paulo, Universidade de São Paulo (IGCE/UNESP), Brasil. Tese de doutorado. 1997.

Campos, H.C. Águas subterrâneas da Bacia do Paraná. GEOSUL, N.37, 2004, p. 47-65.

Celligoi, A.; Duarte, U. Aspectos hidrogeoquímicos da Formação Serra Geral em Londrina- PR. Anais do $7^{\circ}$ Congresso Brasileiro de águas subterrâneas, ABAS.1992. p .425-433.

Chae, G. T.; Yun, S.T.; Mayer, B.; Kim, K.H.; Kim, S.Y.; Kwon, J.K.; Kim, K.; Koh, Y. Fluorine geochemistry in bedrock groundwater of South Korea. Science of the Total Environment, 2007. v.385, 2007. p. 272283.

Costa, A. B.; Lobo, E.A.; Kirst, A.; Soares, J.; Goettems, C.H. Estudo Comparativo da Concentração de (F-), pH e Condutividade Elétrica da Água Subterrânea dos Municípios de Santa Cruz do Sul, Venâncio Aires e Vera Cruz, RS, Brasil. In: Anais do XIII Congresso Brasileiro de Águas Subterrâneas/ABAS. 2004. Cuiabá, MT. CD-ROM, p.16.

Costa Santos, A. Noções de Hidroquímica. Hidrogeologia, Conceitos e Aplicações. Organização e Coordenação Científica Fernando A.C. Feitosa, João Manoel Filho, Edilton Carneiro Feitosa, J. Geilson A. Demétrio 3a . EdiçãoRevisada e Ampliada, CPRM Serviço Geológico do Brasil/ LABHID (2008). Capítulo 5.1 Noções de Hidroquímica. p. 325-357.

Dissanayake, C.B. Water quality and dental health in the dry zone of Sri Lanka. In: Appleton, J.D.; Fuge, R.; McCall, G.J.H. (Ed.). Environmental geochemistry and health. London: The Geological Society, 1996. (GSL Special Publications, 113). p. 131-140.

Drever, J.I. The geochemistry of natural waters: surface and groundwater environments. Prentice Hall. 3rd ed. 1997. 436p.

Dutra, C. M. Aspectos qualitativos da água subterrânea no Campus da UFSM, Santa Maria RS. 138f. Dissertação (Mest. em Eng. Civil). UFSM, CT, PPGEC, RS. 2005.

Flores, E. L. M.; Duarte, F. A.; Paniz, F. N. G.; Silvério da Silva, J. L.; Dressler, V. L. Utilização de Pirohidrólise para a determinação de (F-) em fertilizantes e sal mineral. In: Livro de resumos: 26 $6^{\underline{a}}$ Reunião Anual da Sociedade Brasileira de Química, 2003.

Fraga, C.G. Origem de fluoreto em águas subterrâneas dos sistemas Aquíferos Botucatu e Serra Geral da Bacia do Paraná. São Paulo: Instituto de Geociências, Universidade de São Paulo, Tese de Doutorado, 1992, p. 178.

Frank, H. T.; Gomes, M.E.; Formoso, M. L.L.; Garcia, G.G. Contaminação de (F-) dos Aquíferos da Bacia do Paraná Derivada da Desgaseificação de Intrusivas da Formação Serra Geral: Nova Hipótese. In: Anais do XV Encontro Nac. Perf. de Poços e I Simpósio de Hidrogeologia do Sudeste. ABAS, Gramado, RS. 2007, CD-ROM, p.12.

Freitas, M.A. (org.) PROESC: Diagnóstico dos recursos hídricos subterrâneos do Oeste do Estado de Santa Catarina - Projeto Oeste de Santa Catarina/ Organizado do por Marcos A. de Freitas; Bráulio R. C.; José L. F. Machado. Porto Alegre: CPRM/SDM-SC/SDA-SC/EPAGRI. 2003.

Füchtbauer, H. (Ed.) Sediment und Sedimentgesteine: 1-1141. Schweizerbartsche Verlagsbuchhandlung, Stuttgart. 1-1141

Gaciri, S. J.; Davies, T.C. The occurrence and geochemistry of fluoride I some natural waters of Kenya. Journal of Hydrology, 1993, v. 143, p. 395412.

Giardin, A.; Faccini, U. F. Complexidade hidroestratigráfica e estrutural do Sistema Aquífero Guarani: abordagem metodológica aplicada ao exemplo da área de Santa Maria- RS, Brasil. Revista Águas Subterrâneas/ABAS; n. 18, 2004. 39-54 p.

Goffermann, M. Caracterização hidrogeológica e hidroquímica das águas subterrâneas da Região de São Gabriel, RS. Dissertação de Mestrado, Instituto de Geociências, Programa de Pós-graduação em Geociências, IGEO/ UFRGS, Porto Alegre, 2013. $137 f$.

Guo, L.; Wang, Y.; MA; T. MA, R. Geochemical processes controlling the elevated fluoride concentrations in groundwaters of the Taiyuan Basin, Northern China. Journal of Geochemical Exploration, 2007, v. 93, p. 1-12.

Handa, B.K. Geochemistry and Genesis of FluorideContaining Ground Waters in India. Groundwater. Vol. 13. N0.3, May-June, 1975, p.275-281.

Hem, J.D. Study and Interpretation of the Chemical 
Characteristics of Natural Water. 3rd Ed. U.S. Geological Survey Water-Supply - Paper 2254. USGS - Department of the Interior, United States Government Printing Office, 1985.

Hypholito, R.; Izaki, S.; Aguilar, A. P. Fluoreto nas águas subterrâneas dos Aquíferos Tubarão e Cristalino, região de Salto- Inadaiatuba (SP), 2010. Disponível em: http://www.scielo.br/pdf/re/v63n4/ a18v63n4.pdf.

Hurtado, R. and Gardea-Torresdey, J. Environmental evaluation of fluoride in drinking water at "Los Altos de Jalisco", in the central Mexico region. Journal of Toxicology and Environmental Health, Part A, 2004. 67, 1741-175.

Kern, M.L.; Vieiro, A.P.; Machado, G. The fluoride in the groundwater of Guarani Aquifer System: the origin associated with black shales of Paraná Basin. Environmental Geology, v. 55, n.6, 2008. p. 12191233.

Kimmelmann A. A.; Rebouças, A. C.; Souza, J. C. S.; Rebouças, A. M.; Bastos F., F. W.; Heine, C. A. Considerações sobre anomalias de fluoreto no Sistema Aquífero Botucatu-Pirambóia, na Bacia do Paraná. In: Congresso Brasileiro de Águas Subterrâneas, 6. Anais... Porto Alegre: ABAS, 1990, p. 107-111.

Kim, K.; Jeong, G. Y. Factors influencing natural occurrence of fluoride-rich groundwaters: a case study in the southeastern part of the Korean Peninsula. Chemosphere, 58, 2005, p. 1399-1408.

Iritani, M. A.; Ezaki, S. As águas subterrâneas do Estado de São Paulo. Secretaria de Estado do Meio Ambiente-SMA, 2008. 104p. il. Color.

IPT Relatório Interno. № 40.675, Diagnóstico da situação atual dos Rec. Hídricos e estabelecimento de diretrizes técnicas para elaboração do Plano de Bacia Hidrográfica do Rio São José dos Dourados. Rel Final, 251p. 1986.

Jacks, G.; Rajagopalan, K.; Alveteg, T.; Jönsson, M. Genesis of high-F groundwaters, Southernn India. Applied Geochemistry. Suppl. Issue. No.2, 1993, pp.241-244.

Jacks, G.; Bhattacharya, P. High-fluoride groundwaters in India. Symposium; Keynote address at SCRAP Conference, New Delhi, 1999. $2 p$.

Lisboa, N. A.; Menegotto, E. Condicionantes geoquímicos do Sistema Aquífero Serra Geral no RS, Brasil. In: Anais do V Cong. de Geoquímica dos Países de Língua Portuguesa e VII Cong. Bras. Geoquímica, Salvador, 1999. p. 134-136.

Lobo, E.; Costa, A. B. Análise descritiva da concentração de íons fluoretos em poços artesianos da Região do Vale do Rio Pardo e Rio Taquari, RS, Brasil. Revista Tecnológica, vol.2 n²0: UNISC, jul/ dez.1998.

Lobo, E.; Baccar, N. M.; Costa, A.B. Kirst, A. Estudo da qualidade da água de poços artesianos da região do Vale do Rio Pardo, RS, Brasil. REDES, Santa Cruz do Sul, 4, 2, 1999, 57-72.

Machado, J. L. F. Compartimentação espacial e arcabouço hidroestratigráfico do Sistema Aquífero Guarani no Rio Grande do Sul. Universidade do Vale do Rio dos Sinos. Programa de Pós-Graduação em Geologia. (Tese de Doutorado). São Leopoldo. 2005. 237 p.

Machado, J. L. F e Freitas, M. A. Mapa Hidrogeológico do Estado do RS, escala de 1:750.000. Convênio CPRM Serviço Geológico do Brasil/Secretaria Estadual do Meio Ambiente/SEMA/Departamento de Recursos Hídricos/DRH. Relatório e Mapa. 200

Maddock, J.E.L.; Dias, R.B. Hydrogeochemical prospecting for fluorite in the Serra do Mar, Brazil. In: Congresso Brasileiro de Geoquímica, 2. 1989, Rio de Janeiro. Anais. Rio de Janeiro: SBGq; CPRM; DNPM, 1989. p. 61-68.

Maddock, J.E.L.; Dias, R.B. Prospecção hidrogeoquímica para fluorita, no Estado do Rio de Janeiro. In: Simpósio Brasileiro de Geoquímica, 3, 1985, Ouro Preto. Anais...Ouro Preto: Revista da Escola de Minas, ano LII, v. XLI, n. 1-4, p. 174-188, 1989.

Magalhães, M. Levantamento de poluição com Flúor em pastagens de gado nas vizinhanças de olaria Município de Itaboraí- RJ. 1982. 60 p. Dissertação (Mestrado em Geoquímica) Universidade Federal Fluminense, Niterói, 1982.

Mancuso, M. A.; Schroeder, J. K.; Silvério da Silva, J. L. Análise dos teores de (F-) nas águas de abastecimento Público nos Municípios localizados sobre o Aquífero Serra Geral. In: XX Simpósio Brasileiro de Recursos Hídricos, 2013, Bento Gonçalves. In: XX Simpósio Brasileiro de Recursos Hídricos. Porto Alegre: ABRH, 2013.

Mancuso, M. A.; Schroeder, J. K.; Silvério da 
Silva, J. L.; Ribeiro, L. F, T. 474 - Aplicação da geoestatística às ocorrências de íon fluoreto nas águas de abastecimento público de municípios localizados no Aquífero Serra Geral, no Noroeste do Rio Grande do Sul, Brasil. In: 12ํㅡㄹ Congresso da Água/16ํㅡㄹ ENASB/XVI SILUBESA, APRH, 2014, Lisboa, Portugal.

Mayer, R.A. A. Paleoalterites and Paleosols by Robert Mayer, A. A. Balkema Uitgevers BV, Rotterdam, 1997. No. of pages: vi + 151.. ISBN 9054107243.

Marimon, M. P. C. O Flúor nas águas subterrâneas da Formação Santa Maria, na região de Santa Cruz do Sul e Venâncio Aires, RS, Brasil. Porto Alegre: Instituto de Geociências da UFRGS, (Tese de Doutorado). 2006. 165p.

Marion, F. A.; Capoane, V.; Silvério da Silva, J. L. Avaliação da qualidade água subterrânea em poço do Campus da UFSM, Santa Maria, RS. Ciência e Natura, Revista do CCNE, Santa Maria,volume 29 (1), 2012, p.97-109.

Marion, F. A. Avaliação da vulnerabilidade das águas subterrâneas por Geoprocessamento, no Campus da UFSM-RS, 94f. Dissertação (mestrado em Geomática) UFSM, CCR, Programa de PósGraduação, CCR, Santa Maria, RS,2009, 94f.

Marion, F. A. Avaliação da vulnerabilidade das águas subterrâneas por Geoprocessamento, no Campus da UFSM - RS, 94f. Dissertação (mestrado em Geomática) UFSM, CCR, Programa de PósGraduação em Geomática, RS. 2009.

Marion, F. A.; Mello Filho, J. A.; Silvério da Silva, J. L. Análise da vulnerabilidade natural das águas subterrâneas por geoprocessamento no Campus da UFSM - RS. Revista Terr@Plural. (UEPG. Online), v.4, 2010, p.65- 76 .

Mestrinho, S. S. P. Monitoramento em Águas Subterrâneas. In: FEITOSA, F. A. C.; MANUEL FILHO, J. Hidrogeologia: Conceitos e Aplicações. CPRM. $3^{\circ}$ ed. cap. 7.2., 2008, p. 673-685.

Milani, E. J.; Rangel, H. D.; Bueno, G. V.; Stica, J. M.; Winter, W. R.; Caixeta, J. M.; Pessoa Neto, O.C. Bacias Sedimentares Brasileiras- Cartas Estratigráficas- Introdução. Boletim de Geociências Petrobrás, Rio de Janeiro, v. 15, n.2, maio/nov.2007. p. 183-205,

Mocellin, R. C. Conectividade e Compartimentação Magnética-Estrutural dos Sistemas Aquíferos Serra Geral e Guarani na Região Sudoeste do Estado do
Paraná (Bacia do Paraná, Brasil). Dissertação de Mestrado UFPR. Departamento de Geologia 2009, p. $199+$ Anexos.

Moraes, E. L. M.; Duarte, F. A.; Paniz, J. N.; Silvério da Silva, J. L.; Flores, E. M. M.; Dressler, V. L. Utilização da pirohidrólise para a determinação de (F-) em fertilizantes e sal mineral. In: 26를 Reunião Anual da Sociedade Brasileira de Química, 2003. Poços de Caldas/Minas Gerais. 26ª Reunião Anual da Sociedade Brasileira de Química.

Nanni, A. S. O flúor em águas do Sistema Aquífero Serra Geral no Rio Grande do Sul: origem e condicionamento geológico. In: Semana Acadêmica de alunos de Pós-Graduação em Geociências. 2006, Porto Alegre, Resumos... UFRGS, p.101-10.

Nanni, A. S. O flúor em águas do Sistema Aquífero Serra Geral no Rio Grande do Sul: origem e condicionamento geológico. Tese de doutorado Universidade Federal do Rio Grande do Sul. Instituto de Geociências. Programa de PósGraduação em Geociências. 2008a. p.127. Disponível em: <http://hdl.handle.net/10183/13785>. Acesso em 05 janeiro 2014.

Nanni, A. S.; Roisenberg, A.; Fachel, J. M.G.; Mesquita, G.; Danieli, C. Fluoride characterization by principal component analysis in the hydrochemical facies of Serra Geral Aquifer System in Southern Brazil. Anais da Academia Brasileira de Ciências. 2008b, 80(4): 693-701. (Annals of the Brazilian Academy of Sciences). ISSN 0001-3765. Disponível em: www.scielo.br/aabc. Visitado em 3/01/2014.

Nanni. A. S.; Roisenberg, A.; De Hollanda, M. H. B. M.; Marimon, M. P. C.; Viero, A. P; Scheibe, L. F. Fluoride in the Serra Geral Aquifer System: Source Evaluation Using Stable Isotopes and Principal Component Analysis. Journal of Geological Research. Volume 2013, Article ID 309638. 9 pages. Disponível em: http://dx.doi. org/10.1155/2013/309638. Visitado em 10/01/2014.

Ojeda, C. G y González, C. E. Origen y evolución del (F-) en el acuífero aluvial del valle de Aguascalientes, México. In: Anais $4^{\circ}$ Cong. Lat. de Hid. Subterrânea, ALHSUD, 1998. Vol. 3, p.12291245

Organização dos Estados Americanos/OEA. Aquífero Guarani Programa Estratégico de Ação/PEA. Bilíngue Português e Espanhol. 2009. p. 424, CDROMs. 
Panagoulias, T. I.; Silva Filho, E. V. Estudo hidrogeoquímico do flúor nas águas subterrâneas das bacias dos Rios Casseribú, Macacu e São João, Estado do Rio de Janeiro. In: SILVA, C.R., Figueiredo, B.R., Capitani, E.M., Cunha, F. G. (Org.). Geologia Médica no Brasil. Efeitos dos materiais e fatores geológicos na saúde humana e meio ambiente. Rio de Janeiro: CPRM, 2006, v. 1, p. 126-129.

PSAG - Projeto de Proteção Ambiental e Desenvolvimento Sustentável do Sistema Aquífero Guarani. Acuífero Guaraní: avances en el conocimiento para su gestión sustentable. Montevidéo. 2007. p. 396.

PSAG - Projeto de Proteção Ambiental e Desenvolvimento Sustentável do Sistema Aquífero Guarani. Manual de perfuração de poços tubulares para investigação e captação de água subterrânea no "Sistema Aquífero Guarani". Montevidéo. 2007. $107 \mathrm{p}$.

PSAG - Síntese Hidrogeológica do SAG. Série Manuais e Documentos Técnicos do PSAG. Equipe Técnica de Editoração e Produção Gráfica: TDA Comunicação 2009a. p.102.

PSAG - Aquífero Guarani: Programa Estratégico de acción Acuífero Guaraní: Programa Estratégico de Acción. Ed. bilíngue. Brasil; Argentina; Paraguai; Uruguai: (OEA), janeiro 2009b. 424 p. ISBN: 978-8598276-07-6.

PSAG - Projeto de Proteção Ambiental e

Desenvolvimento Sustentável do Sistema Aquífero Guarani. Tomo 2. Inventario y Muestreo, isotopia. Hidroquimica Zona Sur y Norte. Isotopia. Volumen 8, tomo2: Informe final de Hidroquimica Regional. Hidroquimica Regional del SAG Estudio del Origen de la Composición Química de las Aguas Subterráneas del Sistema Acuífero Guaraní. Manzano, M.; Guimaraens, M. 2009c, p. 212.

PSAG - Projeto de Proteção Ambiental e Desenvolvimento Sustentável do Sistema Aquífero Guarani. II Congresso do Aquífero Guarani, Ribeirão Preto, SP. 4-7 de Novembro de 2008. Disponível em: http://www.ambiente.sp.gov. br/institutogeologico/files/2012/03/IIConSAG_ nov2008.pdf. Visitado em 10/02/2013.

Santiago, M.R. e Silvério da Silva, J. L. Flúor em Águas Subterrâneas: Um Problema Social. In: XVIII Simpósio Brasileiro de Recursos Hídricos, 2009, p.15.

Santiago, M. R. Análises das ocorrências anômalas de fluoreto em águas subterrâneas. Dissertação (Mestrado) - Universidade Federal de Santa Maria. Programa de Pós-graduação em Eng. Civil e Recursos Hídricos, 2010. P.104.

Santiago, M. R. e Silvério da Silva, J. L. Variabilidade na concentração de elementos químicos em poço único. In: Conferência Internacional. A gestão do SAG: um exemplo de cooperação, São Paulo. IGc/ USP, 2011a. Sessão Pôster. v. 1. p.28.

Santiago, M.R. e Silvério da Silva, J.L. Classificação Hidroquímica de Águas Subterrâneas do Sistema Aquífero Guarani no RS e SC. In anais do XIII Congresso Brasileiro de Geoquímica- III Simp. Geoq. Países do Mercosul, RS, Out. BR. 2011b, P.1041-1044.

Sartori, P.L. P.; Silvério da Silva, J. L.; Kawashita, $\mathrm{K}$. Idades radiométricas K/Ar e indicações sobre a área fonte das micas dos arenitos fluviais da Formação Sanga do Cabral. In: Simpósio sobre cronoestratigrafia da Bacia do Paraná $\left(2^{\circ}\right)$, UFRGS, PORTO ALEGRE, Boletim de Resumos Expandidos. 1995. p. 111-113.

Scheibe, L. F. e Hirata, R.C.A. O contexto tectônico dos Sistemas Aquíferos Guarani e Serra Geral em Santa Catarina: uma revisão. In: XV Congresso Brasileiro de Águas Subterrâneas. Natal, RN. In; Anais do XV Congresso Brasileiro de águas subterrâneas. ABAS, 2008. CD-ROM.

Schroeder, J.K.; Mancuso, M.A.; Flores, B.A; Griebler, J.S.; Strojaki, T.V. Avaliação da ocorrência de concentrações anômalas de (F-) nas águas de abastecimento público do município de Frederico Westphalen -RS. 28o Salão de Iniciação Científica, 16 a 18 de outubro de 2013, UFSM. Santa Maria, Brasil. 5p.

Silva, G. R.B. 1983. Estudo hidrogeoquímico e isotópico das águas subterrâneas do Aquífero Botucatu no Estado de São Paulo, Tese de doutoramento. Instituto de Geociências, USP, p.133, 9 pranchas.

Silvério da Silva, J. L.; Menegotto, E.; Medeiros, E. R. Avaliação preliminar dos Argilominerais das Folhas de Camobi e Santa Maria, RS. Ciência e Natura. v. 12, 1990. p. 127-132.

Silvério da Silva, J. L. 1997. Estudo dos processos de silicificação e calcificação em rochas sedimentares Mesozóicas do Estado do Rio Grande do Sul, Brasil, Curso de Pós-Graduação em Geociências, UFRGS, Tese de doutorado em Geociências. p. 156, XLVI 
pranchas e 107 figuras.

Silvério da Silva, J. L.; Flores, E. M.M.; Bertazzo, V.M. Estudo hidroquímico das águas subterrâneas da região de Santa Maria, no Estado do RS. In: XXVII Congresso Interamericano de Engenharia Sanitária e Ambiental. Porto Alegre, PUC, 2000, p.10.

Schroeder, J.K.; Mancuso, M.A.; Flores, B.A; Griebler, J.S.; Strojaki, T.V. 2013. Avaliação da ocorrência de concentrações anômalas de flúor nas águas de abastecimento público do município de Frederico Westphalen -RS. 28o JAI, out. 2013, UFSM. Santa Maria, Brasil. 5p.

Silvério da Silva, J. L.; Bessouat, C.; Camponogara, I.; Guimaraens, M.; Frantz, L. C.; Gamazo, P.; Failache, L., Caracterização de áreas de recarga e descarga do SAG em Rivera - Livramento e Quaraí - Artigas. Estudo da vulnerabilidade em área de influência de Artigas - Quaraí. Informe Final. Projeto №10, Fundo das Universidades. 2 Volumes. Português. Disponível em: http://www.ufsm.br/labhidrogeo. 2006, 2 Volumes. Disponível em: http://www.ufsm. br/labhidrogeo.

Silvério da Silva, J. L.; Hirata, R. C. A.; Flores, E. L. M.; Dressler, V. L. Novas Hipóteses sobre a Origem de Flúor no Sistema Aquífero Guarani na Depressão Central Gaúcha, Brasil. In: Anais do Congresso Brasileiro de Águas Subterrâneas, Florianópolis, 2002. CD-ROM.

Silvério da Silva, J. L.; Dressler, V. L.; Riffel, E. S.; Santiago, M. R. Ocorrências anômalas de flúor em águas subterrâneas do Sistema Aquífero Guarani no Estado do RS. In: V Seminário LatinoAmericano e I Iberoamericano de Geografia Física. Santa Maria - RS, 2008.

Silvério da Silva, J. L.; Santiago, M. R.; Gamazo, Pablo. Concentrações anômalas de flúor no SAG. In: Conferência Internacional. A gestão do SAG: um exemplo de cooperação, São Paulo: IGc/USP, 2011a. Sessão Poster. v. 1. p. 27.

Silvério da Silva, J.L.; Santiago, M.R.; Dressler, V. L. Concentrações Anômalas de Fluoretos em Águas subterrâneas do Sistema Aquífero Guarani. In: Anais do XIII Congresso Brasileiro de GeoquímicaIII Simp. Geoq. Países do Mercosul, Gramado-RS, Out. 2011b, p. 1037-1040.

Sracek, O. and Hirata, R. C. A. Geochemical and stable isotopic evolution of the Guarani Aquifer System in the state of São Paulo, Brazil.
Hydrogeology Journal 10: 643-655.

Soares, A. P.; Soares, P. C.; Holz, M. Correlações Estratigráficas Conflitantes no Limite PermoTriássico no Sul da Bacia do Paraná: O Contato Entre duas Sequências e Implicações na Configuração Espacial do Aquífero Guarani. Revista Pesquisas em Geociências, Porto Alegre, UFRGS. (2008a). 35 (2): 115-133, 2008.

Soares, A. P.; Soares, P. C.; Holz, M. Heterogeneidades hidroestratigráficas no Sistema Aquífero Guarani. Revista Brasileira de Geociências. (2008b). Dez. 2008. 38(4): 598-617.

Toassi, R.F.C.; Abegg C. Fluorose dentária em escolares de um município da serra gaúcha, Rio Grande do Sul, Brasil. Cad. Saúde Pública [online]. 2005, vol.21, n.2, p 625-655.

Torres-Ruiz, J.; Galindo, A.L.; López, J.M.G.; Delgado, A. Geochemistry of Spanish sepiolite-palygorskite deposits: Genetic considerations base on trace elements and isotopes. Chemical Geology, 112 (1994) 231-245.

Velásquez, L. N. Flúor na água subterrânea e fluorose dental no município de São Francisco, Minas Gerais. In: Cong. Bras. Geologia, 41, João Pessoa. In: Anais. João Pessoa, 2002, p. 554.

Velásquez, L.N.; Costa, W.D.; Fantinel, L.M.; Uhlein, A.; Ferreira, E.F.; Castilho, L.S. Controle estrutural do fluoreto no Aquífero Cárstico do Município de São Francisco, MG. In: Cong. Bras. Águas Subterrâneas, 13, Anais Cuiabá: 2006, 26p.

Vengosh, A.; Pankratov, I. $\mathrm{Cl} / \mathrm{Br}$ and $\mathrm{Cl} / \mathrm{F}$ ratios of domestic sewage effluents and associated contaminated groundwater. Ground Water 36 (5), $1998,815-824$.

Wang, Y.; Stepen, L. S.; Su. C. Genesis of arsenic/ fluoride-enriched soda water: A case study at Datong, northern China Applied Geochemistry 24. 2009. P. 641-649.

Wedepohl, K. W.; Correns, C. W.; Shaw, D. M.; Turekian, K. K. e Zemann, J. Handbook of Geochemistry. Springer-Verlag Berlin, 1972. p. 56A-2.

WHO/ World Heath Organization. Fawell,J.; Bailey, K. J.; Chilton, E. Dahi; Fewtrell, L. and Magara, Y. Fluoride in Drinking-water. World Health Organization titles with IWA Publishing. Printed by TJ International (Ltd.), Padstow, Cornwall, UK. 
2006, 144p. Disponível em: http://apps.who.int/ iris/bitstream/10665/43514/1/9241563192_eng.pdf. Visitado em 10/02/2014.

Zanatta, L. C. e Coitinho, J. B. L. Utilização de poços profundos no Aquífero Guarani para abastecimento público em Santa Catarina. In: XII Cong. Bras.

Águas Subterrâneas. ABAS. Florianópolis. 2002. 16 p. CD-ROM. 